OPERATIONAL ESTIMATION AND PREDICTION OF NITRIFICATION DYNAMICS IN THE ACTIVATED SLUDGE PROCESS

M.B. Beck

International Institute for Applied Systems Analysis, Laxenburg, Austria

RR-82-7

March 1982

Reprinted from Water Research, volume 15 (1981)

INTERNATIONAL INSTITUTE FOR APPLIED SYSTEMS ANALYSIS

Laxenburg, Austria 
Research Reports, which record research conducted at IIASA, are independently reviewed before publication. However, the views and opinions they express are not necessarily those of the Institute or the National Member Organizations that support it.

Reprinted with permission from Water Research 15:1313-1330, 1981.

Copyright $\odot 1981$ Pergamon Press Ltd.

All rights reserved. No part of this publication may be reproduced or transmitted in any form or by any means, electronic or mechanical, including photocopy, recording, or any information storage and retrieval system, without permission in writing from the copyright holder. 


\section{FOREWORD}

In previous decades, managing water quality in river basins has generally been regarded as a matter of planning and design. However, more recently a wide variety of problems, dominated by their growing scale and increasingly complex structure, has shown that the objectives for water quality management cannot always be achieved by planning and design alone. This raises the question of the feasibility of operational aspects of water quality management.

Since this question is being faced in a number of countries, it has been one of the principal themes of the work of the International Institute for Applied Systems Analysis on environmental quality control and management.

In 1979 IIASA undertook to investigate issues related to real-time (operational) water quality management. Part of this work was to investigate what strategy is feasible in the light of the states of the relevant arts. In this regard the Institute was aided by a group of 14 experts from 11 countries who met together in March 1980 and assisted in the work's later developments.

The principal product of this cooperation was a report offering an overview of the possibilities to an audience of officials, technical experts, and planners: M.B. Beck, Operational Water Quality Management: Beyond Planning and Design (Executive Report 7, IIASA, 1981).

The present paper provides supporting material of a more technical nature for some of the problems, approaches, and recommendations discussed in the Executive Report. It deals with on-line monitoring, estimation, and forecasting in the context of wastewater treatment plant operational control, and examines problems associated with process failures due, for example, to accidental spillages of toxic materials.

JANUSZ KINDLER

Chairman

Resources and Environment Area 


\title{
OPERATIONAL ESTIMATION AND PREDICTION OF NITRIFICATION DYNAMICS IN THE ACTIVATED SLUDGE PROCESS
}

\author{
M. B. BECK \\ International Institute for Applied Systems Analysis, Schloss Laxenburg, \\ A-2361, Laxenburg, Austria
}

(Received March 1980)

\begin{abstract}
This paper examines the feasibility and discusses the potential of applications of on-line real-time state estimation and prediction in operational control of the activated sludge process. In particular, the dynamics of nitrification are considered with reference to the activated sludge unit at the Norwich Sewage Works in eastern England. A recursive estimation algorithm, the extended Kalman filter, is applied both for reconstructing operating information on the variations in nitrifying bacterial population concentrations and for making predictions of process performance under assumed scenarios for the short-term future operating conditions of the plant. Time-series field data from the Norwich Works are used for the former analysis. Considerations of uncertainty and the possibility of rapid major perturbations in performance, for example, due to spillages of toxic substances or the loss of solids over the clarifier weir, are of special importance to the discussion. The paper is introduced and concluded with some more general comments on the roles of operator experience and decision-making and manmachine interaction in wastewater treatment plant control.
\end{abstract}

$C(t)=$ time-variable compaction ratio for solids passing through clarifier

$C^{*}=$ time-invariant compaction ratio for solids passing through clarifier

$k_{1}, k_{2}=$ specific decay-rate constants for Nitrosomonas and Nitrobacter respectively $\left(\right.$ day $\left.^{-1}\right)$

$K_{1}, K_{2}=$ saturation concentrations for Nitrosomonas and Nitrobacter respectively $\left(\mathrm{g} \mathrm{m}^{-3}\right)$

$p=$ coefficient of solids-liquids separation efficiency in clarifier;

$Q_{1}, Q_{R}, Q_{W}=$ influent settled sewage, recycle sludge, and waste sludge flow-rates, respectively $\left(\mathrm{m}^{3}\right.$ day $\left.^{-1}\right)$

$t=$ time (days)

$u_{1}=$ concentration of ammonium $-\mathrm{N}$ in influent settled sewage $\left(\mathrm{g} \mathrm{m}^{-3}\right)$

$V_{A}=$ volume of aerator $\left(\mathrm{m}^{3}\right)$

$x_{i}=$ component concentration in the aerator: $i=1$, ammonium- $\mathrm{N} ; i=2$, nitrite- $\mathrm{N}$; $i=3$, nitrate- $\mathrm{N} ; i=4$, Nitrosomonas bacteria; $i=5$, Nitrobacter bacteria (all in $\mathrm{g} \mathrm{m}^{-3}$ )

$\mathbf{x}=$ vector of state variables

$x_{4 R}, x_{5 R}=$ concentrations of Nitrosomonas and Nitrobacter bacteria in recycle sludge, respectively $\left(\mathrm{g} \mathrm{m}^{-3}\right)$

$Y_{1}, Y_{2}=$ yield coefficients for Nitrosomonas and Nitrobacter respectively (g organism produced/g substrate consumed);

$\mathbf{y}=$ vector of measured output variables

$\alpha=$ vector of model parameters

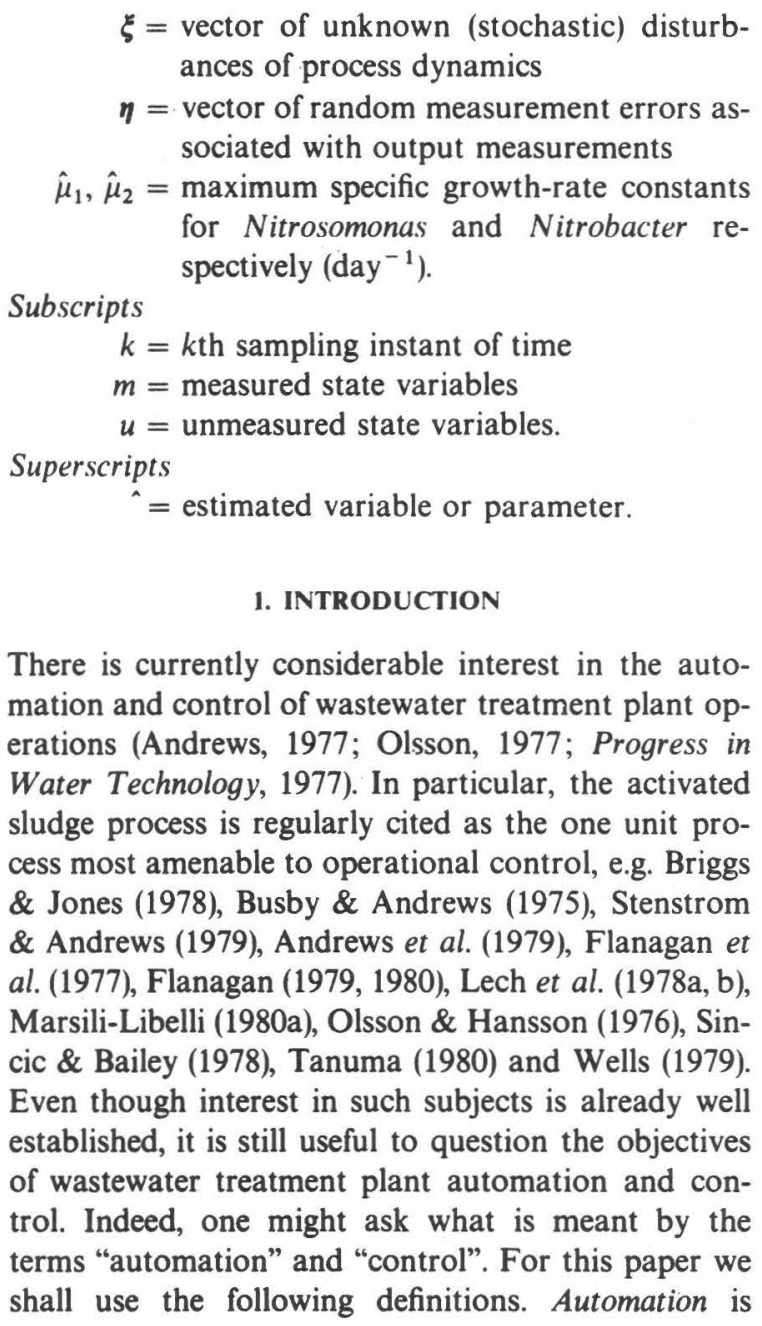


understood as the automation of information retrieval about process conditions, e.g. on-line sensors, and the automation of implementing control actions, e.g. turning on and off pumps, blowers, and scrapers. Control is the activity that links together these two automated functions: it is the use of the information retrieved for determination of the control actions to be implemented. As indicated in a recent appraisal by Hegg et al. (1978), the incentive to automate and control wastewater treatment facilities lies with the desire to achieve "design performance", or better, through adequate day-to-day operation. Such adequate operation does not depend entirely on "automation"; it depends upon the application of "control" as defined above.

Early work by Briggs (1967) demonstrated the feasibility of controlling dissolved oxygen (DO) concentration in the aerator basin of an activated sludge unit. Closed-loop control of both the DO profile and the volume of recycled sludge are now relatively commonplace. However, these individual control loops by no means imply complete process control. In fact, it is debatable whether unit treatment processes can or should be placed under totally closed-loop control. Suppose, as would be pragmatic, that the human element-the plant manager or operator-is retained in the control loop. How much more effective would his control decisions be if the information retrieved from the on-line sensors were restructured in useful ways? For example, assuming the availability of a computing facility, what is the potential for using on-line mathematical models and information processing algorithms in:

(i) rapid evaluation of the short-term future consequences of various control actions;

(ii) prediction of future events, typically the expected variations in quality and flow-rate of the settled sewage influent to the aerator;

(iii) statistical estimation of process performance from error-corrupted measurements; and the reconstruction of information about process variables that may be important for the control function but which are not directly measured by instruments, e.g. the concentrations of nitrifying bacteria.

These kinds of question have recently attracted interest elsewhere (e.g. Briggs \& Jones, 1978; Flanagan, 1979, 1980; Holmberg \& Ranta, 1978; Butler \& Andrews, 1980); they provide the motivation for this paper. In terms of Fig. 1, therefore, we shall be concerned principally with the use of models as information processing mechanisms. The use of models in evaluating and determining suitable control actions will be of lesser importance to the paper.

In 1977 a small collaborative project was initiated by the Anglian Water Authority (U.K.) and the University of Cambridge. The project was to undertake a study of dynamic modelling and operational control of the activated sludge unit at the Norwich Sewage Works in eastern England. Preliminary results of the project are reported in Beck et al. (1978). The present paper examines in greater depth the problems of estimating and predicting the dynamics of nitrification in the activated sludge process. In particular, emphasis is placed on exploring the potential for applying on-line (real-time, or recursive), estimation/ prediction algorithms in the context of operational control. The algorithm used here for this purpose is the extended Kalman filter (EKF) (e.g. Jazwinski, 1970). Specific mathematical details of this algorithm, however, will not be of concern to the paper; rather it is the broad concepts and scope of such algorithms, and how they might be applied in practice, that is of interest. Further results for the calibration (parameter estimation) of the nitrification model are given in Beck (1979a); the application of the model for evaluating an operational control scheme for the activated sludge process is reported in Tong et al. (1980).

The organization of the paper is as follows. Section 2 presents a model for the dynamics of nitrification. In Section 3 the conceptual outlines of on-line estimation and prediction algorithms are introduced together with a brief discussion of the range of problems to which these algorithms are applicable. Section 4 divides into two parts, both of which illustrate the

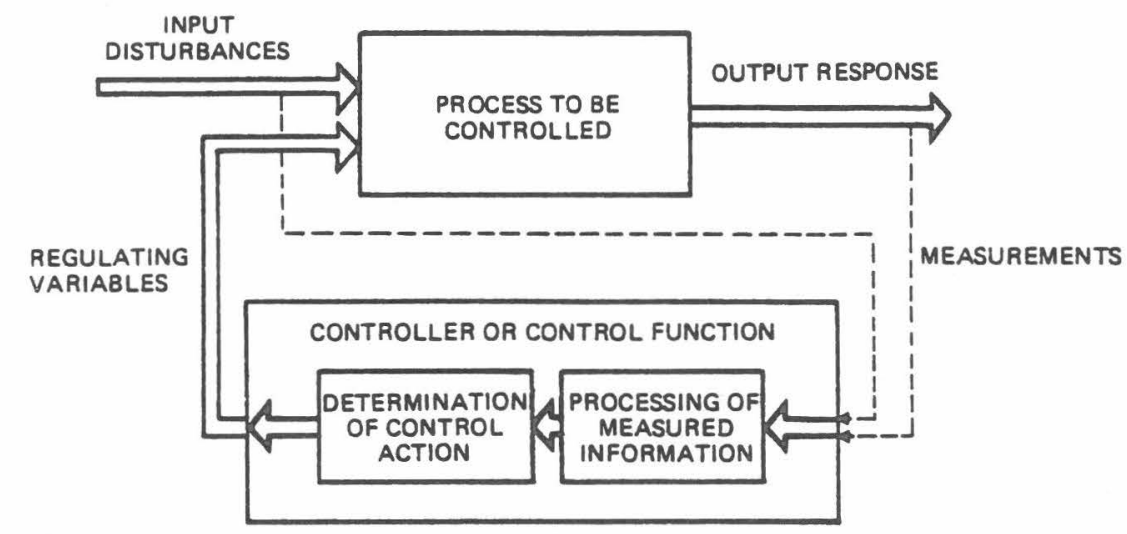

Fig. 1. The basic features of process control; on-line measurements are available for some of the input disturbances and for some of the output responses. 
potential scope for on-line estimation and prediction with reference to the specific case of the plant at Norwich Sewage Works. The first of these two parts deals with the problem of reconstructing on-line estimates of the nitrifying bacterial population concentrations (variables which are not directly measurable), while the second is concerned with evaluating the shortterm future consequences of possible future process disturbances and control actions. Section 5 then discusses the practical relevance of these results, including considerations of microprocessor-based applications and the detection and monitoring of major process disturbances and "failures".

\section{A MODEL FOR NITRIFICATION DYNAMICS}

One reason why models for the nitrification of waste materials are easier to calibrate against experimental data than corresponding models for carbonaceous BOD and SS removal is that in nitrification fairly specific substrates and equally specific groups of micro-organisms can be identified. Moreover, observations of ammonium-, nitrite-, and nitrate-nitrogen concentrations are both less ambiguous and much closer to the "microscopic" kinetic behaviour of interest than are the somewhat "macroscopic" and crude measurements of BOD and SS concentrations. Experience from this case study of the Norwich Sewage Works confirms that it is indeed especially difficult to calibrate dynamic models for the removal of these latter components.

Thus several models for nitrification have been proposed and have been evaluated with considerable success against various types of experimental observations. Qualitatively the basic biochemical model for nitrification shows that ammonium- $N$ is oxidized in two stages to nitrate- $\mathrm{N}$,

$$
\begin{gathered}
\text { Nitrosomonas } \quad \text { Nitrobacter } \\
\text { ammonium- } \mathrm{N} \stackrel{\downarrow}{\longrightarrow} \text { nitrite- } \mathrm{N} \stackrel{\downarrow}{\longrightarrow} \text { nitrate- } \mathrm{N}
\end{gathered}
$$

where Nitrosomonas and Nitrobacter are the mediating species of micro-organism. Under the assumption that the conversion step from ammonium- $\mathbf{N}$ to nitrite- $\mathrm{N}$ occurs more slowly, and is therefore ratelimiting for the overall process, Downing et al. (1968) obtained a simple model, which they assessed with daily observations form laboratory-scale activated sludge units treating domestic sewage. More recently Gujer (1977), Gujer \& Erni (1978) have presented equally good results for a similar model. They demonstrated the ability of their model to simulate diurnal variations characterised by a sequence of 2-h measurements from a pilot plant treating sewage from the city of Zürich. Gujer's model, however, while it also assumes a single-step conversion from ammonium- $\mathrm{N}$ to total oxidized nitrogen, contains a modified kinetic expression. This modification permits the modulation of Nitrosomonas activity according to: (i) the difference in growth-rates of the Nitrosomonas and the sludge as a whole; and (ii) the balance of the distribution of sludge between the aerator and the rest of the unit (Gujer, 1977). Lijklema (1973) also bases his model for nitrification on a single conversion stage, with again ammonium- $\mathrm{N}$ to nitrite- $\mathrm{N}$ being the rate-limiting step, but he includes the possibility of predation of the nitrifiers by populations of protozoa and rotifers. Butler \& Andrews (1980) propose a modification of the expression for nitrifying bacterial population growth-rates by including consideration of the limitation of growth under low dissolved oxygen conditions (see also Stenstrom \& Poduska, 1980). Harleman (1978) and Leonov (1980) consider nitrification in a more general context as only a part of the complete aerobic nitrogen cycle. They propose models that include in addition: particulate organic nitrogen, dissolved organic nitrogen, heterotrophic bacterial conversion of dissolved organic nitrogen to ammonium- $\mathrm{N}$ and uptake and release of nitrogen compounds by phytoplankton and zooplankton. Both these authors have tested their various models against laboratory chemostat data.

The model used for this study is one of intermediate complexity and is identical (in all but two minor respects) with the model of Poduska \& Andrews (1975). Figure 2 gives a schematic diagram of the activated sludge process together with a definition of some of the notation. The major assumptions of the model are listed as follows:

(i) all biochemical reactions take place in the aerator;

(ii) the aerator mixing regime is approximated by a continuously stirred tank reactor (CSTR);

(iii) the species Nitrosomonas and Nitrobacter grow according to a Monod function;

(iv) in the aerator there is no production of ammonium- $\mathrm{N}$ by heterotrophic bacteria acting upon organically bound nitrogen;

(v) no denitrification takes place;

(vi) the only component of interest entering the aerator with the settled sewage is the ammonium-N component;

(vii) the clarifier has no dynamic properties and thus all components are returned instantaneously from the aerator effluent to the aerator recycle influent;

(viii) only the Nitrosomonas and Nitrobacter concentrations are increased by compaction in the settler;

(ix) the rate of nitrification is independent of ambient DO and temperature conditions.

All these assumptions are frequently made by other authors. Assumptions (vii) and (ix), in particular, are not very good assumptions, as will be evident later. They can only be reasonably justified first by pointing out that any hydraulic transients associated with the clarifier appear as virtually "instantaneous" dynamics when compared with the low sampling frequency of the data (once per day). Second, no data were available regarding the daily averages of the mixed liquor 


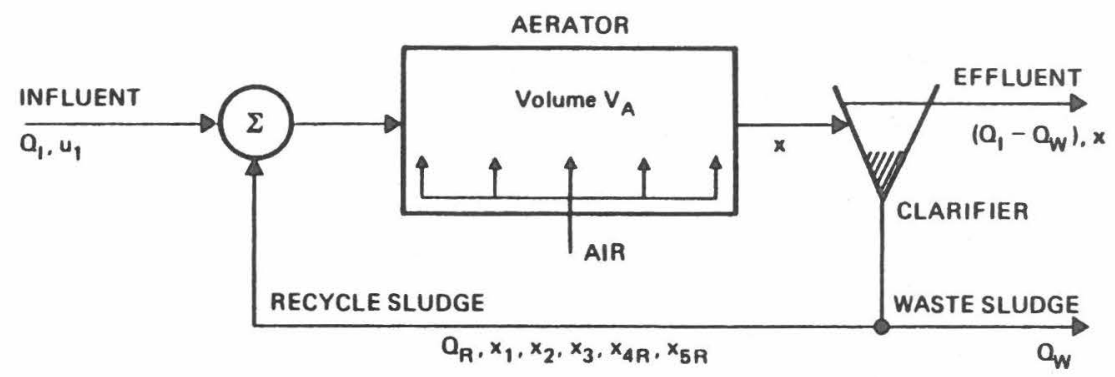

Fig. 2. Schematic diagram of the activated sludge process; all notation is defined in the text.

DO concentration and temperature, although, in this case, intermittent, sampled observations of the former were recorded in the plant manager's operating log book.

Given the above assumptions, component mass balances across the aerator yield the following 5 nonlinear ordinary differential equations for the dynamic nitrification model,

Ammonium-N:

$\dot{x}_{1}(t)=Q_{I}(t)\left(u_{1}(t)-x_{1}(t)\right) / V_{A}-\mu_{1}(t) x_{4}(t) / Y_{1}+\xi_{1}(t)$

Nitrite-N:

$$
\begin{aligned}
\dot{x}_{2}(t)= & -Q_{1}(t) x_{2}(t) / V_{A}+\mu_{1}(t) x_{4}(t) / Y_{1} \\
& -\mu_{2}(t) x_{5}(t) / Y_{2}+\xi_{2}(t)
\end{aligned}
$$

Nitrate-N:

$$
\dot{x}_{3}(t)=-Q_{1}(t) x_{3}(t) / V_{A}+\mu_{2}(t) x_{5}(t) / Y_{2}+\dot{\zeta}_{3}(t)
$$

Nitrosomonas:

$$
\begin{aligned}
\dot{x}_{4}(t)= & \left(Q_{R}(t) C(t)-Q_{I}(t)-Q_{R}(t)\right) x_{4}(t) / V_{A} \\
& +\mu_{1}(t) x_{4}(t)-k_{1} x_{4}(t)+\xi_{4}(t)
\end{aligned}
$$

Nitrobacter:

$$
\begin{aligned}
\dot{x}_{5}(t)= & \left(Q_{R}(t) C(t)-Q_{I}(t)-Q_{R}(t)\right) x_{5}(t) / V_{A} \\
& +\mu_{2}(t) x_{5}(t)-k_{2} x_{5}(t)+\xi_{5}(t)
\end{aligned}
$$

where the dot notation refers to differentiation with respect to time $t$. In equation (2) the growth-rate expressions for Nitrosomonas and Nitrobacter are given respectively by,

$$
\begin{aligned}
& \mu_{1}(t)=\hat{\mu}_{1} x_{1}(t) /\left(K_{1}+x_{1}(t)\right) \\
& \left.\mu_{2}(t)=\hat{\mu}_{2} x_{2}(t) / K_{2}+x_{2}(t)\right)
\end{aligned}
$$

and the other notation is defined by

$x_{i}(t)=$ component concentration in the aerator: $i=1$, ammonium- $\mathrm{N} ; i=2$, nitrite- $\mathrm{N} ; i=3$, nitrate- $\mathrm{N} ; i=4$, Nitrosomonas bacteria; $i=5$, Nitrobacter bacteria (all in $\mathrm{g} \mathrm{m}^{-3}$ )

$u_{1}(t)=$ concentration of ammonium- $\mathrm{N}$ in the settled sewage influent $\left(\mathrm{g} \mathrm{m}^{-3}\right)$

$Q_{I}(t), Q_{R}(t)=$ respectively the influent and recycle flow-rates $\left(\mathrm{m}^{3}\right.$ day $\left.^{-1}\right)$

$V_{A}=$ volume of sewage in the aerator $\left(\mathrm{m}^{3}\right)$

$$
\begin{aligned}
\hat{\mu}_{1}, \hat{\mu}_{2}= & \text { maximum specific growth-rate con- } \\
& \text { stants for Nitrosomonas and Nitro- } \\
& \text { bacter respectively }\left(\text { day }^{-1}\right) \\
Y_{1}, Y_{2}= & \text { yield coefficients for Nitrosomonas } \\
& \text { and Nitrobacter respectively (g organ- } \\
& \text { ism produced per } \mathrm{g} \text { substrate con- } \\
& \text { sumed) } \\
K_{1}, K_{2}= & \text { saturation concentrations for Nitroso- } \\
& \begin{array}{l}
\text { monas and Nitrobacter respectively } \\
\\
\left(\mathrm{g} \mathrm{m}^{-3}\right)
\end{array} \\
k_{1}, \mathrm{k}_{2}= & \text { specific decay-rate constants for } \\
& \begin{array}{l}
\text { Nitrosomonas and Nitrobacter re- } \\
\text { spectively (day } \left.{ }^{-1}\right)
\end{array} \\
\xi_{i}(t)= & \text { random input unknown disturbance } \\
& \text { for each state variable }\left(\mathrm{g} \mathrm{m}^{-3} \text { day }^{-1}\right) .
\end{aligned}
$$

Finally, $C(t)$ is defined as being the equivalent of a compaction ratio for the Nitrosomonas and Nitrobacter. $C(t)$ can be obtained by taking a component mass balance across the clarifier for either species, i.e.

$$
\begin{aligned}
& \left(Q_{I}(t)+Q_{R}(t)\right) x_{4}(t)=\left(Q_{I}(t)\right. \\
& \left.\quad-Q_{W}(t)\right)(1-p) x_{4}(t)+\left(Q_{R}(t)+Q_{W}(t)\right) x_{4 R}(t)
\end{aligned}
$$

in which $p$ is defined as a coefficient of solids-liquids separation efficiency, $Q_{W}(t)$ is the sludge wastage rate $\left(\mathrm{m}^{3} \mathrm{day}^{-1}\right)$, and $x_{4 R}(t)$ is the concentration of Nitrosomonas in the recycle sludge stream $\left(\mathrm{g} \mathrm{m}^{-3}\right)$. Rearranging equation (4) gives the recycle Nitrosomonas concentration in terms of the aerator Nitrosomonas concentration,

$$
x_{4 R}(t)=\left\{\frac{Q_{R}(t)+p Q_{I}(t)+(1-p) Q_{W}(t)}{Q_{R}(t)+Q_{W}(t)}\right\} x_{4}(t)
$$

from which we define

$$
C(t) \triangleq\left\{\frac{Q_{R}(t)+p Q_{I}(t)+(1-p) Q_{W}(t)}{Q_{R}(t)+Q_{W}(t)}\right\} .
$$

The above balance for compaction of bacterial species in the clarifier is accounted for respectively by the terms $\left[Q_{R}(t) C(t) x_{4}(t) / V_{A}\right]$ and $\left[Q_{R}(t) C(t) x_{5}(t) / V_{A}\right]$ in equations $(2 \mathrm{~d})$ and $(2 \mathrm{e})$.

Further qualification of the model of equation (2) may be provided by noting that the argument $t$ is retained for all variables that are not assumed to be invariant with time. The two major differences between the present model and the model of Poduska and Andrews are that here the sludge wastage rate 
$\left(Q_{W}\right)$ is not zero and that we have accounted for unknown disturbances $\left(\xi_{i}\right)$ of the process dynamics (this latter therefore places our model in a probabilistic setting).

\section{ON-LINE OPERATIONAL ESTIMATION AND PREDICTION}

It has been stated that a key feature of the current study is the restructuring of measured information. Moreover, if such information processing is to be carried out in an on-line (real-time) fashion, the basis of the processing mechanism will most probably be a recursive estimation algorithm (e.g. Gelb. 1974; Young, 1974). The linear Kalman filter (Kalman, 1960; Kalman \& Bucy, 1961) and the extended Kalman filter (EKF) (Jazwinski, 1970), which is of particular interest here, are two examples of recursive estimators. The contemporary literature indicates that applications of recursive estimation in water-related fields are becoming increasingly widespread, e.g. in water resources, hydrology, and hydraulic systems (Chiu, 1978; O'Connell, 1980; Wood, 1980); in-stream quality modelling (Beck \& Young, 1976; Bowles \& Grenney, 1978; Whitehead, 1979; Young \& Whitehead, 1977); in lake water quality modelling (Canale et al., 1980; Jolankai \& Szöllösi-Nagy, 1978; in water quality monitoring network design, Moore, 1973; Lettenmaier \& Burges, 1977; in sewage flow prediction (Beck, 1977); and in fermentation and biological waste treatment processes (Aborhey \& Williamson, 1978; Svrcek et al., 1974).
A simplified conceptual picture of the EKF is shown in Fig. 3. It is appropriate here to comment that the EKF is certainly not the only technique that could be applied to the following problems. In fact, it is one of the more complex of a number of similar algorithms, but its virtue in this discussion is that it allows perhaps the broadest statement of the range of problems to be tackled. Inspection of the information flows into and out of the block labelled "Extended Kalman Filter" reveals that the measured input/output information $\mathbf{u}$ and $\mathbf{y}$ is translated into statistically based estimates of the measurable state variables $\left(\hat{\mathbf{x}}_{m}\right)$, of the state variables that are not easily measured $\left(\hat{\mathbf{x}}_{\mathrm{u}}\right)$, and of the model parameters $(\hat{\alpha})$. Referring back to Figure 2 and equation (2) these vector terms are composed of the following groups of variables and constants:

(a) The measured input disturbances $\mathbf{u}$ include the influent flow-rate and ammonium- $\mathrm{N}$ concentrations, $\left[Q_{l}, u_{1}\right]$ in equation (2);

(b) The measurable state variables $x_{m}$ comprise the concentrations of ammonium-N, nitrite- $\mathbf{N}$, and nitrate- $\mathrm{N},\left[x_{1}, x_{2}, x_{3}\right]$ in equation (2);

(c) The state variables not directly measurable, $\mathbf{x}_{u}$, are the concentrations of the two nitrifying bacterial populations, $\left[x_{4}, x_{5}\right]$ in equation (2);

(d) The model parameter vector $\alpha$ covers all the coefficients $\left[\hat{\mu}_{1}, \hat{\mu}_{2}, Y_{1}, Y_{2}, K_{1}, K_{2}, k_{1}, k_{2}, p\right]$ in equations (2), (3), and (5);

(e) The measured process output $\mathbf{y}$ includes observations of the state variables $\mathbf{x}_{m}$, i.e. the clarified effluent concentrations of ammonium- $\mathrm{N}$, nitrite- $\mathrm{N}$, and

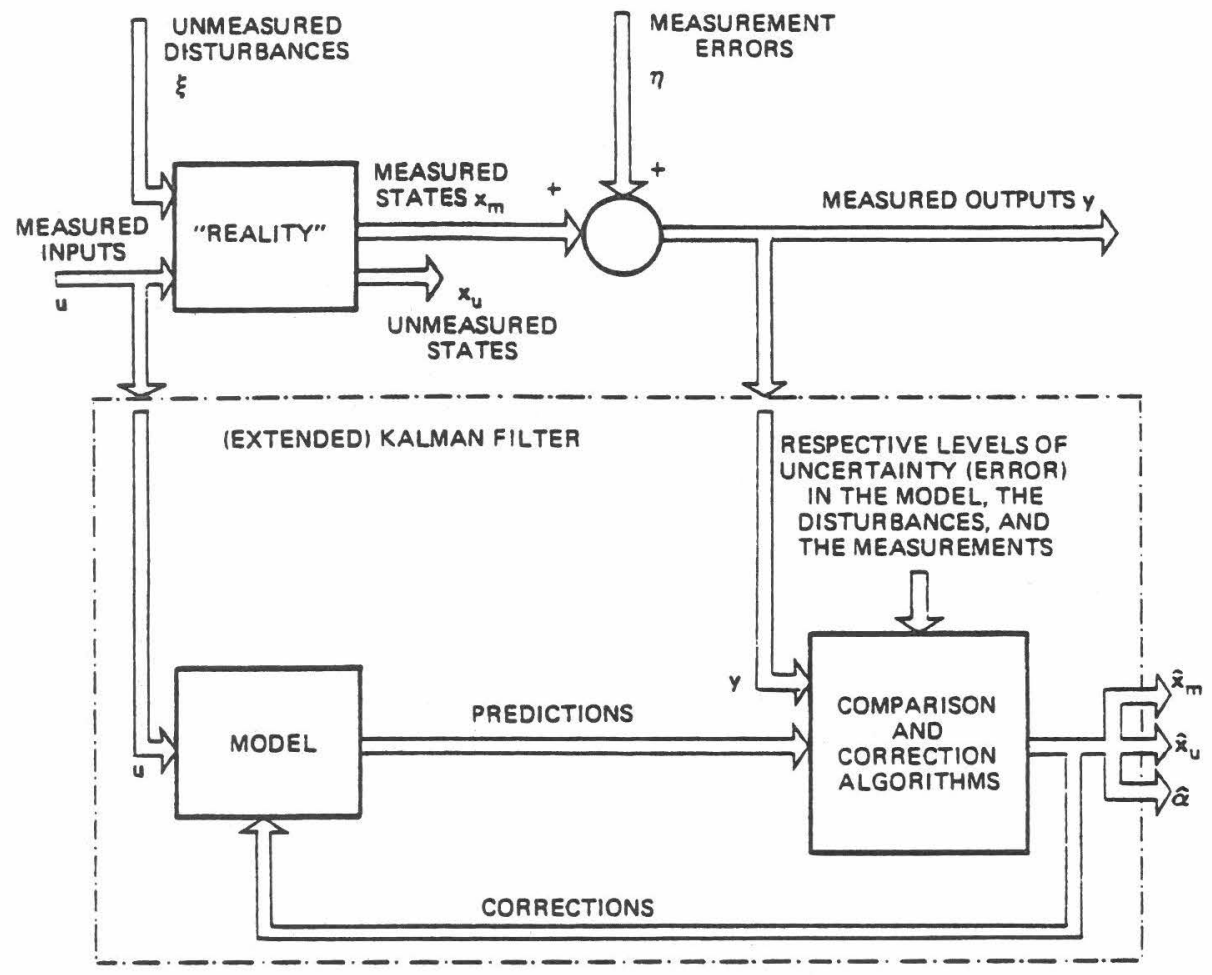

Fig. 3. Conceptual picture of the (extended) Kalman filter. 
nitrate- $\mathrm{N}$, which observations are assumed to include random errors of measurement, so that

$$
\begin{aligned}
& y_{1}\left(t_{k}\right)=x_{1}\left(t_{k}\right)+\eta_{1}\left(t_{k}\right) \\
& y_{2}\left(t_{k}\right)=x_{2}\left(t_{k}\right)+\eta_{2}\left(t_{k}\right) \\
& y_{3}\left(t_{k}\right)=x_{3}\left(t_{k}\right)+\eta_{3}\left(t_{k}\right),
\end{aligned}
$$

where $t_{k}$ indicates the $k$ th discrete instant in time at which the sampled observations are made, and $\eta_{1}, \eta_{2}$, $\eta_{3}$ represent the associated random errors of measurement.

A number of problems of potential interest, and potentially capable of solution with an EKF algorithm, can now be listed as follows:

(i) determination of the structure of the dynamic relationships between inputs $\mathbf{u}$, state variables $\mathbf{x}$, and outputs y (model structure idẻntification);

(ii) computation of values for the parameters $\alpha$ that appear in the identified model structure (parameter estimation);

(iii) determination of the current and future values of the state variables (state estimation and prediction);

(iv) estimation of the inaccessible state variables that are not measured (state reconstruction);

(v) simultaneous determination of the values of $\mathbf{x}$ and $\alpha$ (combined state and parameter estimation. or adaptive estimation and prediction).

Problems (i) and (ii) are clearly directed towards system identification and model calibration (e.g. Beck \& Young, 1976; Beck, 1979b), and will not generally be of concern to this paper. However, a slightly different interpretation of problem (ii) (parameter estimation) will be relevant to the discussion of "failure" detection in Section 5. With respect to problem (v) it is worth noting in passing that an adaptive controller. which can be considered as an extension of problem (ii). combines the functions of both controlling the process and updating the model of process behaviour.

A derivation of the EKF algorithms will not be presented, as we have already said. Sufficient details of this derivation can be found elsewhere, for example, in Jazwinski (1970), Gelb (1974), Young (1974). or Beck (1979c). For the illustrative results of the next section it is more appropriate to consider the following two re-statements of problems (iii) and (iv) above. Thus,

(a) Let us assume that we are gicen all the measured information on process operating conditions, $\mathbf{u}$ and $\mathbf{y}$, up to the current time $t_{k}$, and that we are also gicen the model and estimates $\hat{\alpha}$ of its associated parameters $x$ : the first problem (to be described in Section 4.1) is to determine estimates $\hat{\mathbf{x}}_{m}\left(t_{k} \mid t_{k}\right)$ of the measured state variables and estimates $\hat{\mathbf{x}}_{u}\left(t_{k} \mid t_{k}\right)$ for the inaccessible state variables. In other words, we imagine the situation in which (from Fig. 1) the measured information is being processed in real-time for operational control purposes; further, the provision of information about the status of the nitrifying bacteria is assumed to be of special importance. The notation $\hat{\mathbf{x}}\left(t_{k} \mid t_{k}\right)$ signifies estimates at time $t_{k}$ based upon all the information available up to and including the measurements at time $t_{k}$.

(b) Let us suppose that at time $t_{k}$ we are given an assumed pattern or "scenario" of short-term future influent disturbances $\hat{\mathbf{u}}$ and control actions; the second problem (to be described in Section 4.2) is to determine predictions of the associated future response of the process, in terms of estimated values for the state variables $\hat{\mathbf{x}}\left(t \mid t_{k}\right)$.

Several recent papers have likewise suggested the usefulness of investigating such problems. For instance, Olsson \& Andrews (1978), Flanagan (1979, 1980), and Butler \& Andrews (1980) all draw attention to problem (a), whereas, with respect to problem (b), Briggs \& Jones (1978) note that "... early warning of gross changes in load or the arrival of toxicants could be fed into the [computer] system ... and could permit mathematical modelling techniques to be used effectively to aid [operational] management decisions."

For both of the above problems the role of uncertainty (or error) is important. Hence in Fig. 3 it is indicated that the functioning of the EKF algorithm is dependent upon assumptions about the uncertainties in the process input disturbances (including random disturbances), in the model as an approximation of "reality", and in the process measurements. For the first problem, therefore, the reconstructed estimates of the nitrifier population concentrations will reflect an accounting for the balance between these uncertainties. In the second problem confidence bounds will be computed for the predictions, which in turn depend upon the confidence that can be attached to the model and the assumed "scenarios" for the short-term future.

\section{RESULTS FOR THE NORWICH SEWAGE WORKS}

Daily measurements have been taken from the activated sludge plant at the Norwich Sewage Works for the period 1 January-30 April 1976, a possible total of 121 sampled values for each variable. The salient operating conditions underlying these data are discussed fully in Beck et al. (1978). This period was chosen specifically because it was a time of commissioning new plant, during which the plant manager was assessing alternative strategies for recycle control. Consequently, longer-term "steady" operation had not been achieved and, in the absence of suitably planned experimentation (such as that reported by Olsson \& Hansson, 1976), the expectation was that these historical records would contain significant dynamic perturbations in process performance. In fact there was a gradual increase of aeration rate over these winter months, yet for a substantial portion of the time maximum aeration maintained only low DO concentrations. Some of these problems of commissioning undoubtedly relate to the phases in gain and 
loss of nitrification that are evident in the following results.

\subsection{State estimation and state reconstruction}

Figure 4(a), (b) and (c) respectively show the observations $\mathbf{y}\left(t_{k}\right)$ and state estimates $\mathbf{x}_{m}\left(t_{k} \mid t_{k}\right)$ for the aerator concentrations of ammonium- $\mathbf{N}$, nitrite- $\mathrm{N}$, and nitrate-N. Figure 4(d) and (e) show the reconstructed state estimates $\hat{\mathbf{x}}_{u}\left(t_{k} \mid t_{k}\right)$ for the Nitrosomonas and Nitrobacter-the dashed lines indicate corresponding estimates when $C(t)$, the clarifier compaction ratio is assumed to be constant, say $C(t)=C^{*}$. For the purposes of discussion the total period of observation can be divided approximately into three distinct intervals of interest, i.e. the periods $t_{4} \rightarrow t_{33}, t_{36} \rightarrow t_{58}$, and $t_{67} \rightarrow t_{111}$. First, however, let us discuss the initial conditions of the plant. During the Christmas holiday period, i.e. just prior to day $t_{0}$, an underloaded plant condition had allowed a high level of nitrification to become established, which was succeeded by problems of denitrification and rising sludge in the clarifier. At the beginning of the year, therefore, the plant was deliberately being overloaded (the plant manager's response to the denitrification situation, whereby he hoped to suppress nitrification) and was again receiving normal strength sewage. The ammonium- $\mathrm{N}$ concentration of the settled sewage influent is given in Fig. 5. The sudden drop in nitrification at day $t_{4}$ [visible particularly in Fig. 4(a)] actually resulted from a faulty recycle pump that was operating at less than half its desired capacity.

Between $t_{4}$ and $t_{33}$ both groups of nitrifying organisms are able to recover from the upset caused by the loss of recycled sludge; their population concentrations increase at virtually identical rates. For the same period Fig. $4(\mathrm{~b})$ indicates that the model (embedded in the EKF algorithm) is estimating a consistently higher level of aerator effluent nitrite- $\mathrm{N}$ concentration than was observed in practice. If anything, this suggests that the model's estimated rate of nitrite- $\mathbf{N}$ production is here relatively too high in comparison with the corresponding estimated rate of consumption of nitrite- $\mathrm{N}$.

At about $t_{34}$ the process of re-establishing nitrification is temporarily halted, with an accompanying drop in the levels of Nitrosomonas and Nitrobacter. It is possible to attribute this effect to the following cause. Towards the end of January $\left(t_{30}\right)$ the aeration rate had reached its maximum achievable capacity. Since at the Norwich plant aeration rate is operated under closed-loop control in relation to DO levels, this suggests that for some unknown reason the rate of aeration, even at its maximum capacity, was not satisfying the true oxygen demand. Subsequently, from $t_{34}$ onwards an increasing loss of fine solids over the clarifier weir was observed, which might have been due to the dispersion of the biological floc by excessive agitation accompanying the high rate of aeration, and by $t_{39}$ it was noted by the plant manager that a DO level of $1 \mathrm{~g} \mathrm{~m}^{-3}$ could not be maintained in the aerator. Both the loss of solids and the insufficient oxygen conditions are reasonable "causes" for the unstable nitrification conditions estimated over the period $t_{34} \rightarrow t_{58}$. Moreover, given the higher residual levels of nitrite- $\mathrm{N}$ over this period, it appears that the Nitrosomonas are relatively better at surviving under these unstable conditions - compare the "slopes" in the curves of Figure 4(d) and (e). Although such an argument is speculative, it is nevertheless reassuring to find some appropriate supporting eviderice in a recent discussion of the kinetics of nitrification by Stenstrom \& Poduska (1980). They propose multiplicative-type Monod kinetics for the growth of the nitrifying populations in which both the appropriate nitrogen compound and dissolved oxygen concentrations are assumed to be rate-limiting substrates. According to their analysis of various experimental results a drop in the dissolved oxygen concentration from 1.0 to $0.5 \mathrm{~g} \mathrm{~m}^{-3}$ could easily account for a $25 \%$ reduction in growth-rates. Moreover, they quote other evidence that clearly inaicates a greater sensitivity of the Nitrobacter species to low dissolved oxygen levels. This too is in agreement with the higher rate of growth maintained by the Nitrosomonas population over the period $t_{34} \rightarrow t_{58}$ [see Figure $4(\mathrm{~d})$ and (e)].

The rapid loss of nitrification between $t_{58}$ (about $97 \%$ nitrification) and $t_{67}$ (about $30 \%$ nitrification) is not easily understood. Most probably it results from a combination of a high carbonaceous oxygen demand, which was particularly high over this interval, and an under-aeration of the mixed liquors - the aeration rate was inexplicably low on day $t_{63}$. The apparent change of recycle control policy from a fixed recycle rate to a fixed ratio control which was effected at about day $t_{56}$, could have been an additional coincidental factor of significance. Nevertheless, once again the nitrifying organisms slowly re-establish themselves from $t_{67}$ onwards to $t_{111}$. The Nitrobacter population maintains a more stable growth pattern during this period.

By $t_{112}$, however, conditions have been reversed such that at the end of the experimental period both species of organism have been reduced to very low concentrations and nitrification has more or less ceased (approx. 20\% nitrification). It is possible to speculate, with some accuracy, on the causes underlying this loss of nitrification. The dominant operating conditions over the interval prior to $t_{112}$ were a combination of: unsatisfactory DO levels (less than $1 \mathrm{~g} \mathrm{~m}^{-3}$, with maximum aeration); a poor sludge condition with the absence of ciliates; a steadily decreasing mixed liquor SS concentration, with a loss of solids over the clarifier weir; and hence the decision of the plant manager to reduce recycle sludge rate and to stop sludge wastage altogether. The Easter holiday period - with missing observations for $t_{105} \rightarrow t_{108}$ (incl.)-is marked by a drop in the influent ammonium- $\mathrm{N}$ concentration (see Fig. 5). Then, with a higher recycle rate resumed on $t_{106}, 350 \mathrm{~m}^{3}$ sludge was 
wasted on day $t_{112}$. The "error" of this action, which possibly precipitated the collapse of the nitrifier populations, is substantiated by the fact that on day $t_{113}$ no sludge was wasted. This situation certainly could not have been improved by a suspected spillage of toxic material into the sewer network on the same day.

Two remarks may be added in order to close the discussion of this part of the illustrative case study. First, let us note that the estimation algorithm performs adequately over the periods $t_{69} \rightarrow t_{80}$ and $t_{105} \rightarrow t_{108}$ when there were observations missing from the record (see Fig. 4). The model manages to estimate effluent ammonium- $\mathrm{N}$, nitrite- $\mathrm{N}$, and nitrate- $\mathrm{N}$ concentrations across these intervals with- out excessive deviation from "reasonable" values. None of the results of this section, however, are particularly strong evidence of the adequacy of equation (2) as a model for nitrification dynamics. Such an evaluation requires other types of analysis, some of which are discussed in Beck (1979a), and it was not intended to report on model calibration and verification in the present paper. The estimated parameter values used for the model are given in Table 1. From inspection of Figure 4(d) and (e) one can observe that the performance of the model and estimation algorithm are quite sensitive to the choice of a time-varying or time-invariant clarifier compaction ratio, $C$; the former is found to be more appropriate here. Second, and strictly speaking, the model can only be

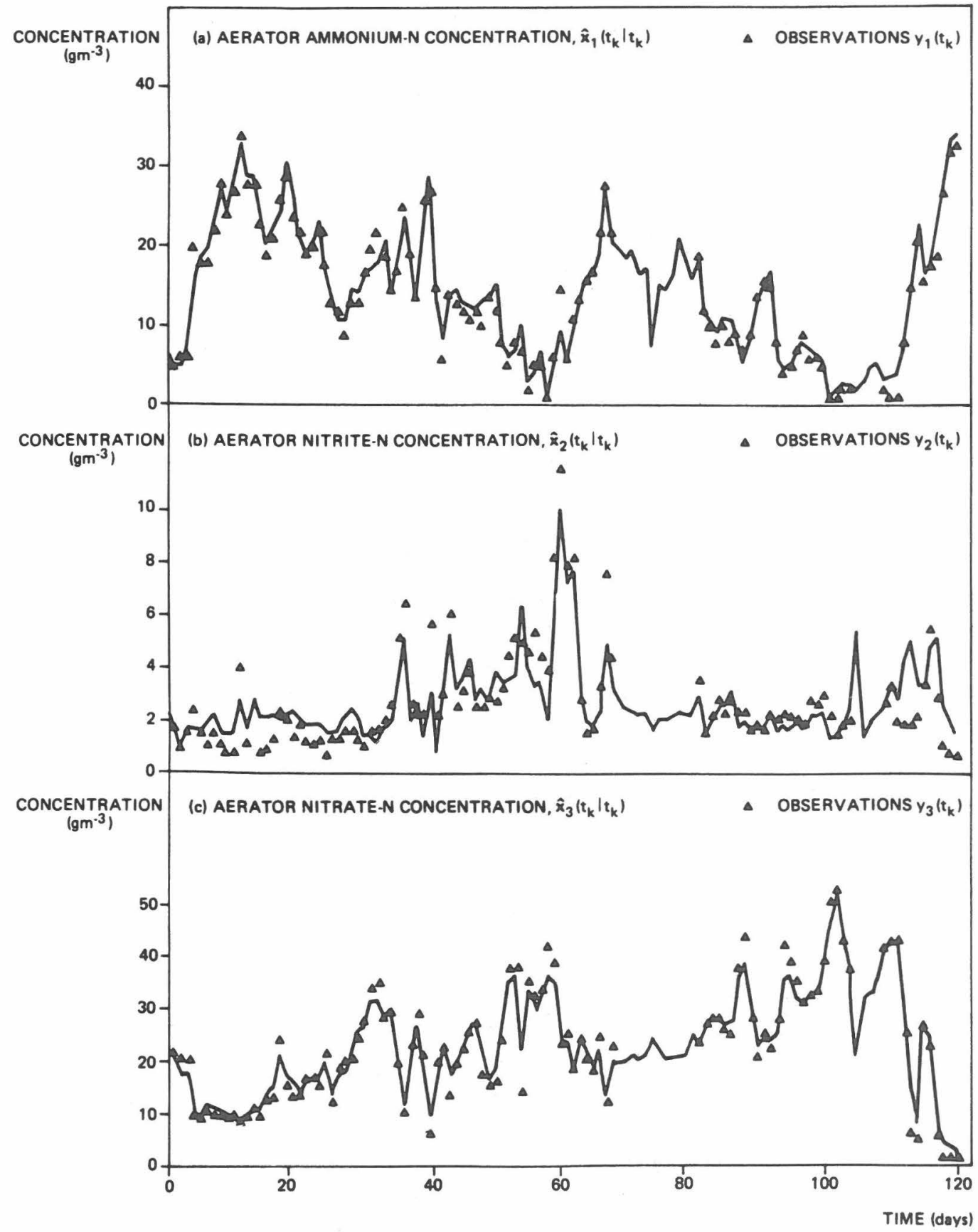




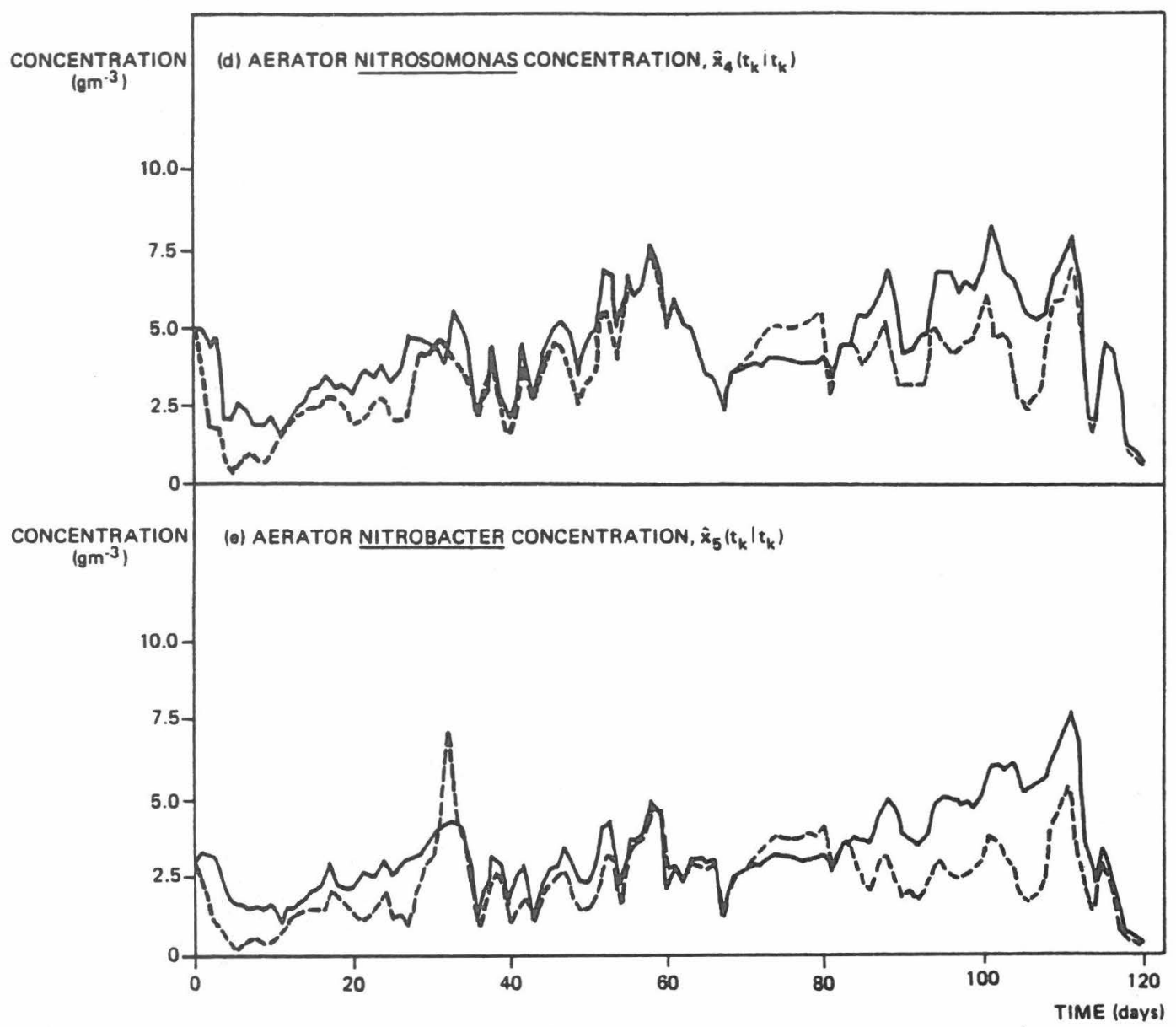

Fig. 4. Observations $y\left(t_{k}\right)$ and state estimates $\hat{\mathbf{x}}_{m}\left(t_{k} \mid t_{k}\right)$ for the aerator concentrations of (a) ammonium-N, (b) nitrite-N, and (c) nitrate-N; reconstructed state estimates $\hat{\mathbf{x}}_{u}\left(t_{k} \mid t_{k}\right)$ for (d) aerator Nitrosomonas concentration and (e) aerator Nitrobacter concentration. The dashed lines in (d) and (e) denote corresponding results when a time-invariant compaction ratio $C^{*}$ is used in the model.

said to be suitable for estimation and prediction of average, day-to-day variations in nitrification. The sampling frequency of the data is once per day, which clearly prohibits the identification of any more rapid variations in behaviour. However, it is apparent from Figure 4(d) and (e), as expected, that the major trends in the growth of the nitrifying populations are estab- lished over periods of weeks and days rather than over fractions of a day.

4.2 Prediction and the evaluation of future operating conditions

Let us turn now to the problem of using the model for evaluating the response of nitrification in the acti-

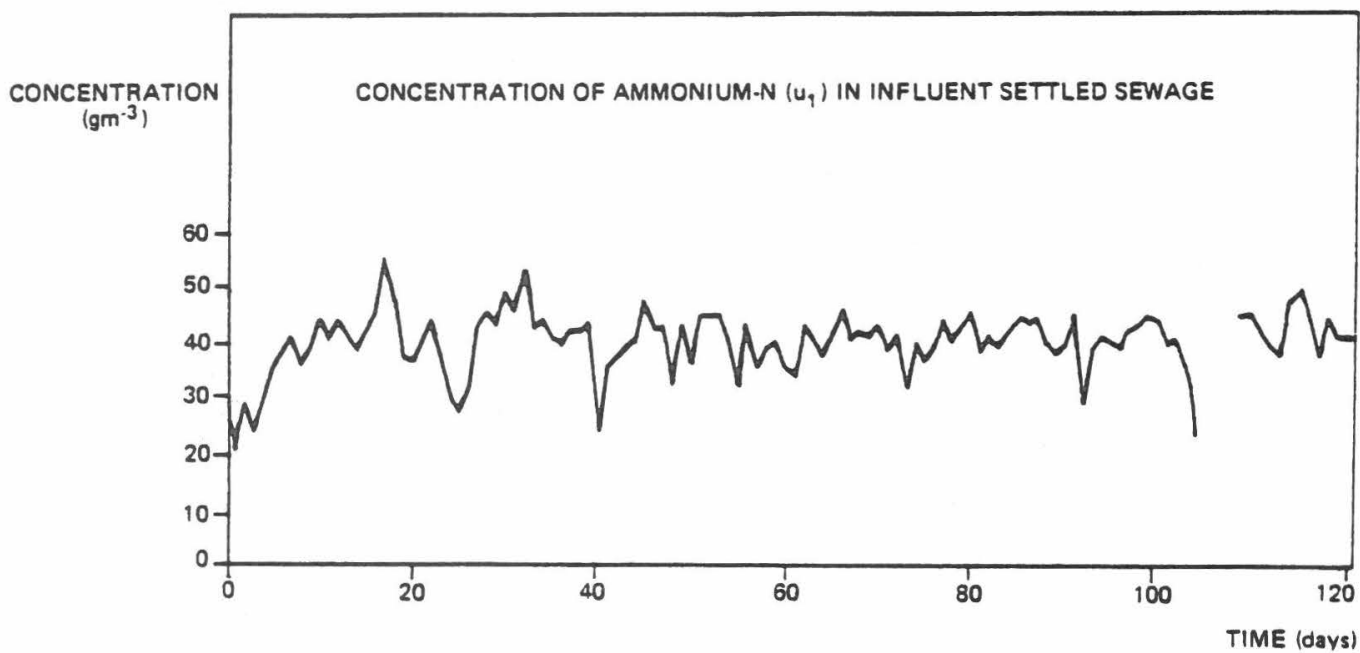

Fig. 5. Concentration of ammonium- $\mathrm{N}$ in influent settled sewage, $u_{1}$. 
Table 1. Parameter estimates for the model of equation (2) and parameter estimates from two sources in the literature

\begin{tabular}{llllc}
\hline & \multicolumn{2}{c}{ Estimate } & Estimate & $\begin{array}{c}\text { Estimate } \\
\text { Parameter }\end{array}$ \\
& $C(t) \dagger$ & $C^{*+}$ & Poduska $\&$ Andrews (1975) & Harleman (1978)s \\
\hline$\hat{\mu}_{1}\left(\right.$ day $\left.^{-1}\right)$ & 0.72 & 0.82 & 1.08 & 1.20 \\
$\hat{\mu}_{2}\left(\right.$ day $\left.^{-1}\right)$ & 0.93 & 1.03 & 1.44 & 1.80 \\
$Y_{1}$ & 0.041 & 0.044 & 0.05 & 0.05 \\
$Y_{2}$ & 0.033 & 0.034 & 0.02 & 0.02 \\
$K_{1}\left(\mathrm{~g} \mathrm{~m}^{-3}\right)$ & 2.5 & 2.5 & 0.063 & 0.6 \\
$K_{2}\left(\mathrm{~g} \mathrm{~m}^{-3}\right)$ & 1.2 & 1.2 & 0.160 & 1.7 \\
$k_{1}\left(\right.$ day $\left.^{-1}\right)$ & 0.2 & 0.2 & 0.12 & 0.2 \\
$k_{2}\left(\right.$ day $\left.^{-1}\right)$ & 0.17 & 0.17 & 0.12 & - \\
$p$ & 0.88 & - & 0.94 & - \\
$C^{*}$ & - & 1.81 & - & - \\
\hline
\end{tabular}

† Time-varying compaction ratio $C(t)$ assumed.

$\ddagger$ Time-invariant compaction ratio $C^{*}$ assumed (value quoted is a mean value computed from the ratio of mixed liquor to recycle sludge SS concentrations).

$\$$ These estimates obtained using the data of Knowles et al. (1965).

Volume of aerator at Norwich Sewage Works $=8320 \mathrm{~m}^{3}$; mean settled sewage influent flow $=2 \times 10^{4} \mathrm{~m}^{3} \mathrm{day}^{-1}$.

Table 2. Assumed values and error statistics for the state variables for the two prediction scenarios*

\begin{tabular}{lc}
\hline \multicolumn{1}{c}{ State variable } & $\begin{array}{c}\text { Initial value and standard } \\
\text { deviation of estimation error } \\
\text { at time } t_{0}\left(\mathrm{~g} \mathrm{~m}^{-3}\right)\end{array}$ \\
\hline Ammonium-N $\left(x_{1}\right)$ & $34.4 \pm 1.7$ \\
Nitrite- $\mathrm{N}\left(x_{2}\right)$ & $1.6 \pm 1.4$ \\
Nitrate-N $\left(x_{3}\right)$ & $2.8 \pm 1.6$ \\
Nitrosomonas $\left(x_{4}\right)$ & $0.85 \pm 0.45$ \\
Nitrobacter $\left(x_{5}\right)$ & $0.49 \pm 0.32$ \\
\hline
\end{tabular}

* Parameter values for the model are as given in Table 1 , for the case of $C(t)$. and for each parameter the standard deviation of the estimation error is assumed to be $5^{\circ}{ }_{0}$ of the parameter value. e.g. $\hat{\mu}_{1}=0.72 \pm 0.036\left(\right.$ day $\left.^{-1}\right)$. vated sludge process to short-term future operating conditions. This is the second of the two problems defined at the end of Section 3.

As a suitable starting point for this illustrative analysis it is most convenient to take the set of actual operating conditions prevailing at the end (day $t_{120}$ ) of the period shown in Fig. 4 and discussed in the preceding section. (From here onwards this will be referred to as time $t_{0}$ for the purposes of prediction.) The plant is in an especially poor state with regard to nitrification, which is in fact virtually negligible, and it would be reasonable to ask, at this point in time, how the plant might recover under future periods of either predominantly "favourable" or "unfavourable" oper-

Table 3. Assumed values and error statistics for the "good" scenario

\begin{tabular}{ll}
\hline Input variables. flow-rates and parameters & $\begin{array}{c}\text { Assumed value and standard } \\
\text { deviation of error }\end{array}$ \\
\hline Influent ammonium-N. $u_{1}\left(\mathrm{~g} \mathrm{~m}^{-3}\right)$ & $45.0 \pm 5.0$ for all $t$ \\
Influent flow-rate. $Q_{r}\left(10^{4} \mathrm{~m}^{3} \mathrm{day}^{-1}\right)$ & $1.90 \pm 0.20$ for all $t$ \\
Recycle flow-rate. $Q_{R}\left(10^{4} \mathrm{~m}^{3} \mathrm{day}^{-1}\right)$ & $1.65 \pm 0.00^{*}$ for all $t$ \\
Sludge wastage rate. $Q_{W} \cdot\left(10^{2} \mathrm{~m}^{3} \mathrm{day}^{-1}\right)$ & $\left\{\begin{array}{l}2.00 \pm 0.00^{*} \text { for } t_{0} \leqslant t \leqslant t_{7} \\
3.00 \pm 0.00^{*} \text { for } t_{7} \leqslant t \leqslant t_{14} \\
4.50 \pm 0.00^{*} \text { for } t \geqslant t_{14}\end{array}\right.$ \\
\hline
\end{tabular}

* Since these are control inputs it is assumed that they are set precisely and without error.

Table 4. Assumed values and error statistics for the "bad" scenario

\begin{tabular}{lc}
\hline \multicolumn{1}{c}{$\begin{array}{c}\text { Input variables. flow-rates } \\
\text { and parameters }\end{array}$} & $\begin{array}{c}\text { Assumed value and standard deviation } \\
\text { of error in assumption }\end{array}$ \\
\hline Influent ammonium-N, $u_{1}\left(\mathrm{~g} \mathrm{~m}^{-3}\right)$ & $35.0 \pm 5.0$ for all $t$ \\
Influent flow rate. $Q_{I}\left(10^{4} \mathrm{~m}^{3} \mathrm{day}^{-1}\right)$ & $2.20 \pm 0.20$ for all $t$ \\
Recycle flow-rate. $Q_{R}\left(10^{4} \mathrm{~m}^{3} \mathrm{day}^{-1}\right)$ & $1.91 \pm 0.00^{*}$ for all $t$ \\
Sludge wastage rate. $Q_{W}\left(10^{2} \mathrm{~m}^{3}\right.$ day $\left.{ }^{-1}\right)$ & $4.50 \pm 0.00^{*}$ for all $t$ \\
Max. Nitrosomonas growth-rate const.. $\hat{\mu}_{1}\left(\right.$ day $\left.^{-1}\right)$ & $0.18 \pm 0.07$ for $t=t_{8}$ (i.e. $40^{\circ}$ orror) \\
Max. Nitrobacter growth-rate const.. $\hat{\mu}_{2}\left(\right.$ day $\left.^{-1}\right)$ & $0.23 \pm 0.09$ for $t=t_{8}$ (i.e. $40^{\circ}$ error) \\
Clarifier efficiency, $p$ & $0.70 \pm 0.09$ for $t=t_{21}$ (i.e. $12 \%$ error) \\
\hline
\end{tabular}

* Since these are control inputs it is assumed that they will be set precisely and without error. 
ating conditions. Thus two scenarios are chosen, one called "good" and the other "bad", the qualititative descriptions of which are given as follows (see also Tables 2, 3 and 4 for quantitative details):

(i) The "good" scenario is characterized by a somewhat lower than average influent flow-rate with above-average ammonium- $\mathrm{N}$ concentration, and a conservative sludge-wasting policy whereby $Q_{W}$ is returned gradually after 2 weeks to a normal value of $450 \mathrm{~m}^{3}$ day $^{-1}$ (see Table 3). For this analysis all quantitative details are based on the typical operating characteristics observed at Norwich during the winter of 1976) (recall also that these characteristics refer only to day-to-day variations).

(ii) The "bad" scenario is characterized by an aboveaverage influent flow-rate with below-average ammonium- $\mathrm{N}$ concentration, and a normal sludge-wasting policy, which one might suppose is chosen by the plant manager in accordance with the objective of maintaining adequate BOD and SS removal performance in the plant (see Table 4). In addition, two abnormal, potential disturbances of the plant are postulated. On day $t_{8}$ there is a pulse-like drop in the bacterial population growth-rates to $25 \%$ of their normal values, which might reflect the effects of temporarily low dissolved oxygen conditions or an accidental spillage of toxic material passing through the plant. Later, on day $t_{21}$, the clarifier efficiency drops to 0.7 , representing the possible effects of a temporary loss of solids over the clarifier weir. Both these latter disturbances are, of course, included for the purposes of illustration; the fact that they are unlikely is reflected in the higher relative errors (uncertainty) attached to the associated parameter values in Table 4. Nevertheless, similar process disturbances were observed in practice (see Section 4.1) and further related discussion will be given in Section 5.

The two scenarios extend to a period of prediction of 40 days and the results for the performance of nitrification are shown in Figs 6 and 7. A comparison of the two scenarios indicates that in general terms nitrification exhibits a good recovery within about 2 weeks under favourable conditions but will barely recover, if at all, under the assumed unfavourable conditions. At the end of the prediction period the error bounds for the "good" scenario have stabilized, after reaching a maximum at the point of maximum growth-rates for the two nitrifying populations. Accordingly, one can be reasonably confident that in this case a high rate of nitrification is assured. In contrast, for the "bad" scenario there is really very little confidence that could be attached to the prediction at the end of the period. It would not be unreasonable to conclude that here the residual ammonium- $\mathrm{N}$ concentration could be anything between a very high level and virtually nothing. This is perhaps not so surprising since rather unlikely events have been specified. However, we may note briefly that there are also certain technicalities associated with the simplified quantification of the estimation error variances that are probably responsible for such rather exaggerated uncertainty. The "accidental" loss of growth and loss of solids from the clarifier are clearly significant upsets, after both of which recovery of the immediately prior nitrification levels takes about 10 days. In the "good" scenario the effects of changing the sludge-wastage rate are hardly discernible, although the return to a normal rate on day $t_{14}$ tends to stabilize performance with nitrification proceeding at a slightly lower level than would otherwise have been maintained with a lower sludge-wastage rate.

The two scenarios chosen for illustration of the model and EKF algorithm are straightforward and, in some senses, restricted examples of what is possible with these techniques. There could indeed be further, more complex speculation in order to evaluate how to manage better the disturbances of the "bad" scenario. However, at this preliminary stage of exploring the potential for such applications, it is more appropriate to begin with considerations that have ultimately a more practical outlook.

\section{FURTHER CONSIDERATIONS}

Four factors are relevant to this discussion of the usefulness of applying in practice the techniques illustrated in the preceding sections:

(i) the distribution of research and development among the three items of on-line observation (instrumentation), information processing, and the facility of implementing control actions (recall Fig. 1);

(ii) necessary compromises among the accuracy, scope, and complexity of the process dynamic model;

(iii) the monitoring of "ideal" behaviour and the detection of "non-ideal" operating conditions.

(iv) the computational effort associated with on-line dynamic models and estimation algorithms.

With respect to the first of these factors, there can be little doubt that the remarkable advances of electronic engineering innovations in water quality management in general have radically improved the capacity to observe and to process data, i.e. to receive operating information. Yet it is innovation of a civil engineering nature-new process designs, and designs geared to operational management-that dominates the capacity to implement control actions. It is unfortunate, since innovation is concerned with change, that there is a rather robust circular argument militating against such possibly desirable change. Operational control systems implemented on process designs that were conceived without due consideration of subsequent operating practice would seem to have a relatively high probability of not being demonstrably beneficial. This in turn may be used to reinforce the conclusion that operational control is not feasible for any process design (see also Olsson, 1980. for a discussion of design-operation interactions). Even if this kind of argument does not apply, how- 
ever, it should be apparent that there ought to be a balanced development of both the capacity to observe and the capacity to act. For example, there is little point in being able to observe in great detail what is wrong without being able to apply corrective action. It is also important, in a more detailed sense, to examine the balance between on-line measuring and information-processing capabilities. One objective, perhaps the most obvious, would be the development of highly accurate sensors for direct measurement of as many variables as possible. A second and complementary objective would be one that is concerned with establishing which variables can be measured $r e$ - liably, exploring thoroughly the kind of information that can be reconstructed from these measurements. and compensating for random and systematic errors as part of the information processing function. Dissolved oxygen concentration, and, by extension, the rate of aeration under closed-loop control conditions, is a prime example of a reliably measured variable with the potential for being highly informative about plant operating conditions. Olsson \& Andrews (1978) have already discussed this point in detail, although their work did not extend to an analysis of the signifcance of dissolved oxygen concentration in relation to nitrification (Stenstrom \& Poduska, 1980), denitrifica-

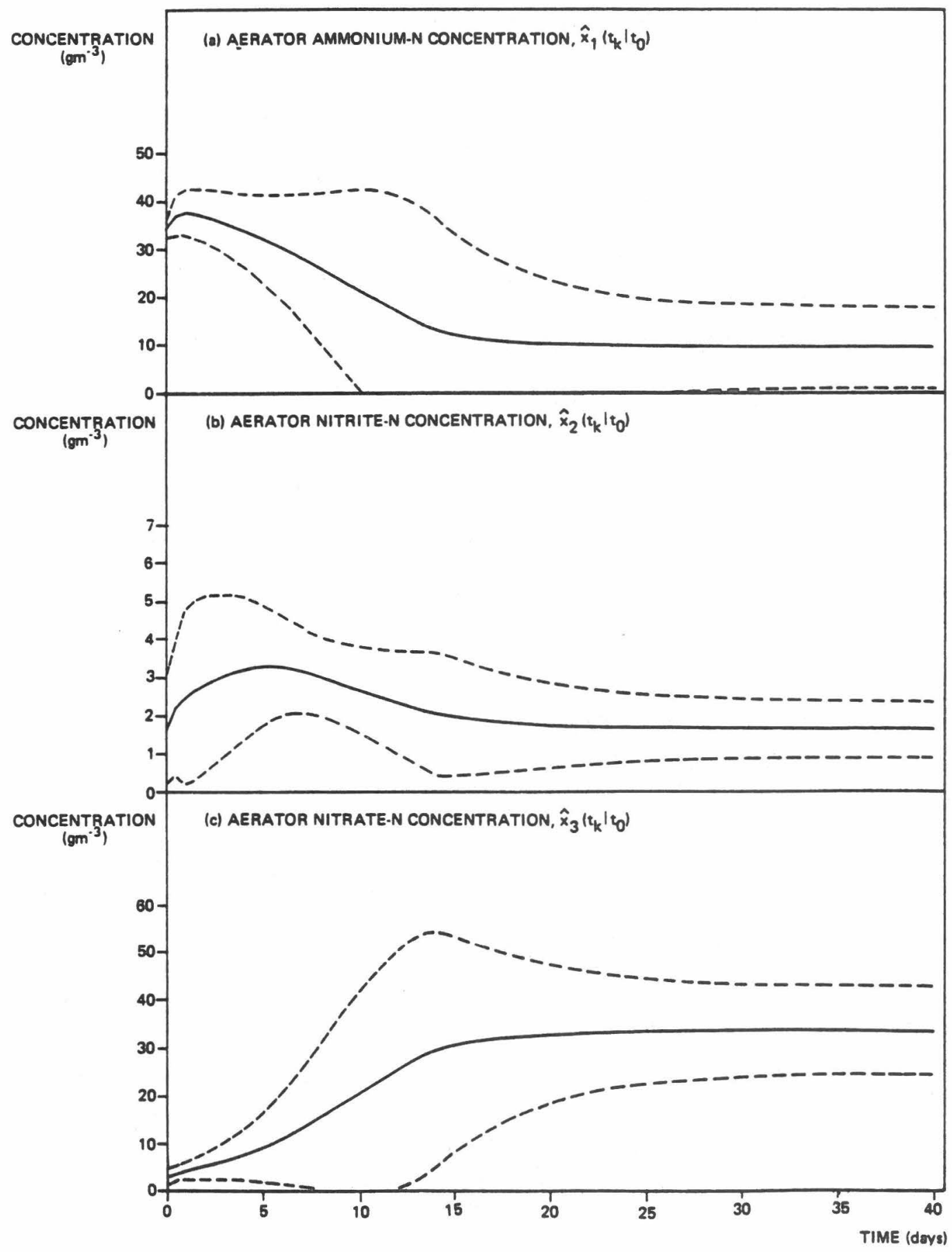




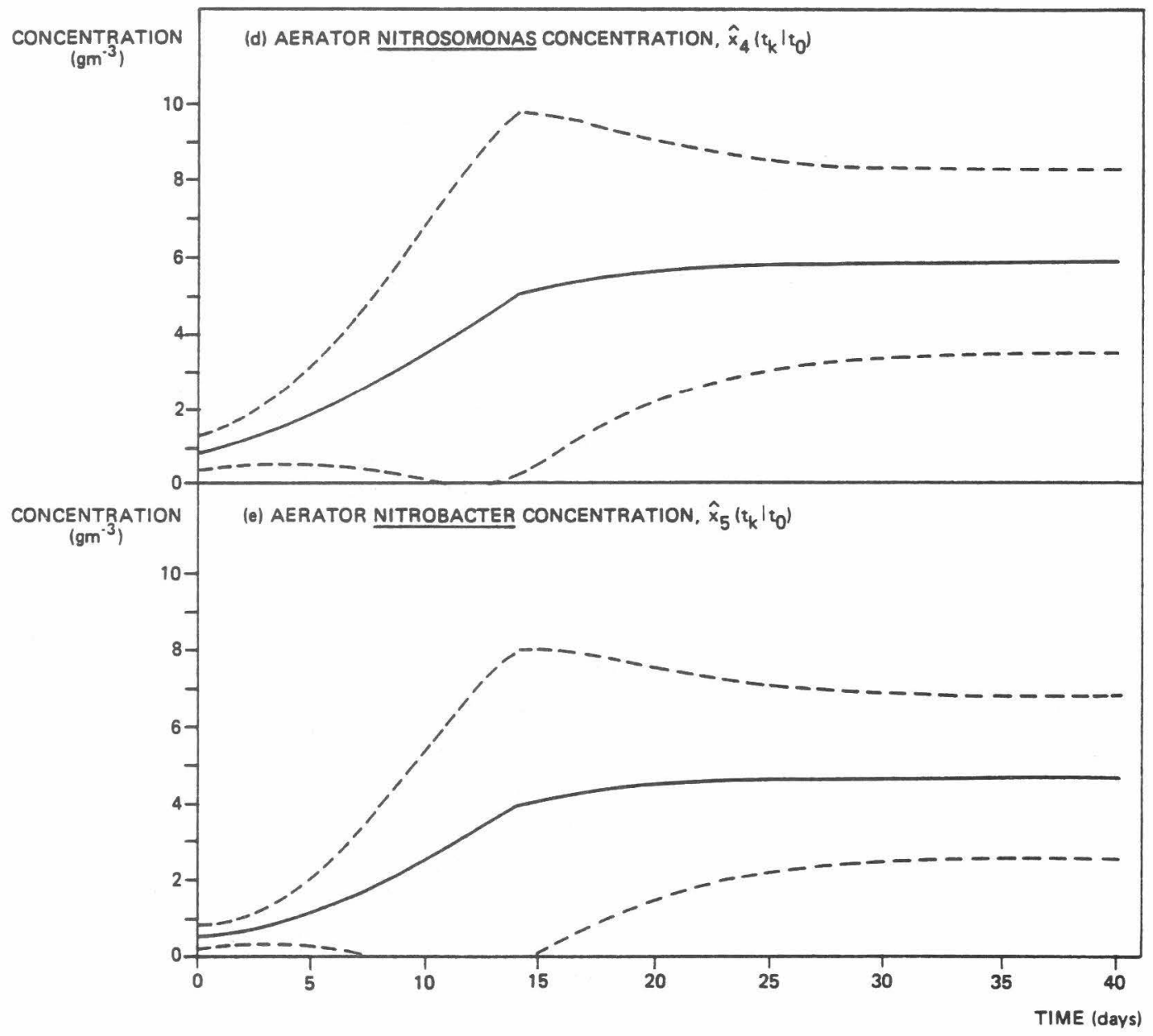

Fig. 6. "Good" scenario: predictions $\hat{\mathbf{x}}\left(t_{k} \mid t_{0}\right)$ for the aerator concentrations of (a) ammonium-N, (b) nitrite-N, (c) nitrate-N, (d) Nitrosomonas and (e) Nitrobacter. The dashed lines indicate the variation of the confidence bounds associated with the predictions (indicated by the standard deviation of the prediction errors).

tion (Matsché, 1977; Paskins et al., 1978), or bulking sludge (Tomlinson \& Chambers, 1979). Clearly thus, as discussed earlier, the strategy underlying the second objective is to shift the burden of providing operating information away from a reliance upon the hardware of sensors towards a reliance upon the software of computing devices. Such a strategy, however, raises at least two important questions: how reliable is this "software", i.e. the model and estimation algorithms; and is there a likelihood of overwhelming the plant manager with too much irrelevant operating information, which would be a highly unreliable policy in the event of "emergency"-type situations?

To answer the first of these two questions let us move to a discussion of the second factor listed above. The dynamic model used in the present study can be criticized on the grounds that in some respects it is too complex and in others too simple. An obvious starting point for simplification, especially in view of the previous studies quoted in Section 2, would be to aggregate the overall process of nitrification into a single step, thereby eliminating the need for a nitrite$\mathrm{N}$ mass balance and combining the two bacterial species into one population. The complexity and scope of the model might then be increased by modifying the growth-rate of the nitrifying population so that it is dependent upon variations in the dissolved oxygen, suspended solids, and $\mathrm{pH}$ levels of the mixed liquors in the aerator. All three of these latter process state variables are considered by various authors to be capable of reliable measurement (e.g. Aarinen et al., 1978; Briggs \& Jones, 1978). Much greater complexity could be added by accounting for the dynamic interactions between nitrification and the other major components of activated sludge behaviour, such as carbonaceous BOD removal, denitrification, phosphorous removal, and the performance of the clarifier, including bulking and rising sludge characteristics. It is clear that compromises between simplicity and accuracy would be inevitable and, in any case, current models of these complex processes are not yet noted for their reliability (in the sense of simulating observed behaviour).

A model, however, is nothing if it is not an idealization and it is therefore useful to examine how a model might be applied as an operational definition of 
"ideal" behaviour. This brings us thus to the third of the above four factors, although it is pertinent first to discuss the following theme developed throughout the paper. In Section 3 the notions of state variable and parameter were introduced; it was also indicated that on-line estimates of both can be obtained at each point in time $t_{k}$. In Section 4.1 constant (time-invariant) estimates of the parameters were assumed for the analysis of historical field data, although the high probability of dissolved oxygen having limited rates of growth would have invalidated this assumption for the maximum specific growth-rate constants (in effect $\hat{\mu}_{1}$ and $\hat{\mu}_{2}$ in the model of equations (2) and (3) are significantly dependent upon DO concentration, which varies with time). Lastly, in Section 4.2 timevarying model parameters were postulated for the representation of major process "failures", or upsets (reduced growth-rate, reduced clarifier separation efficiency), which leads naturally here to considerations of the detection of such obviously "non-ideal" operating conditions. The definition and monitoring of "ideal" behaviour and the detection of "non-ideal" operating conditions are dual problems. How then might the model and on-line estimation algorithms be used to tackle them? The following are useful preliminary guiding principles:

(a) The model should be a simple statement of ideal

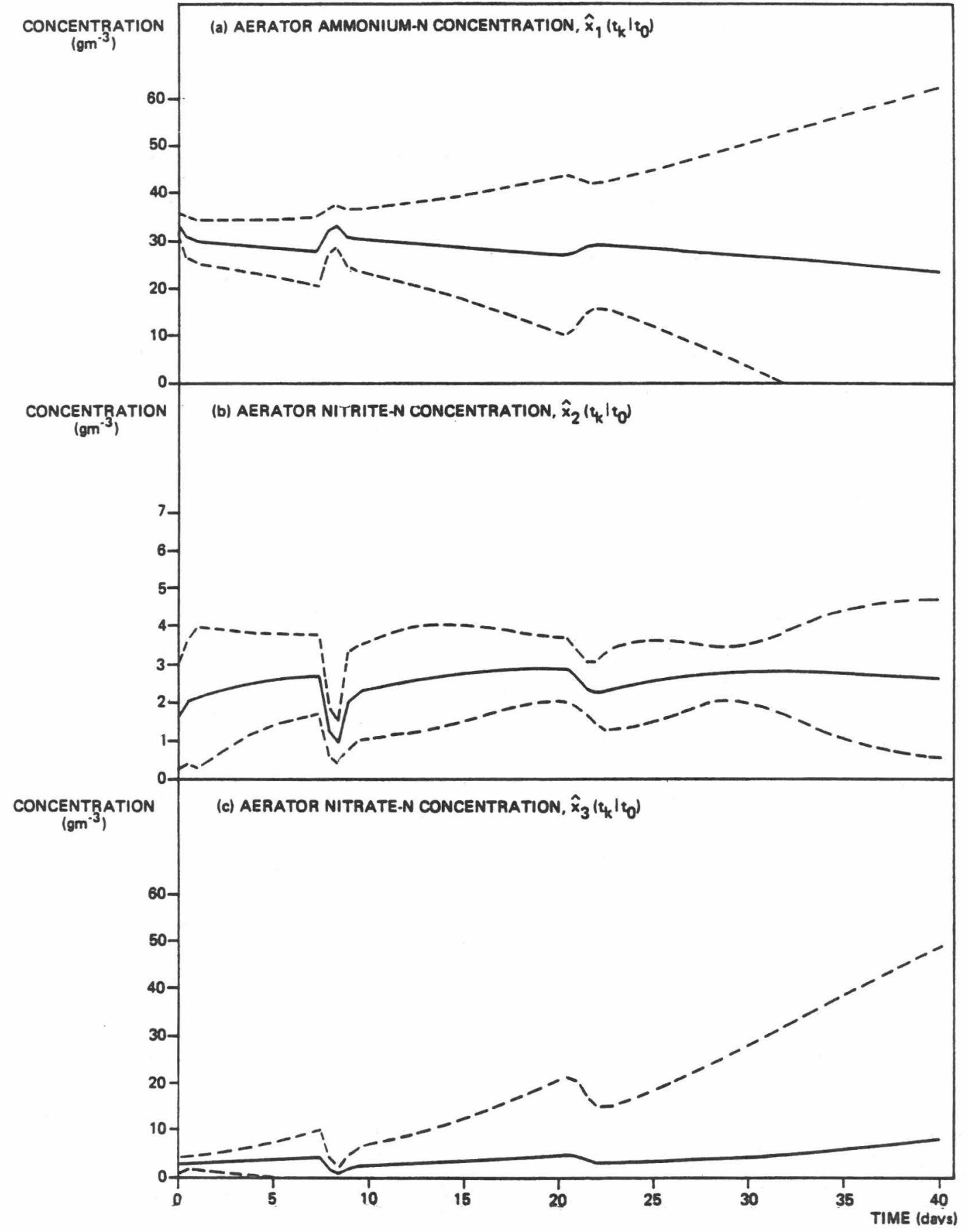




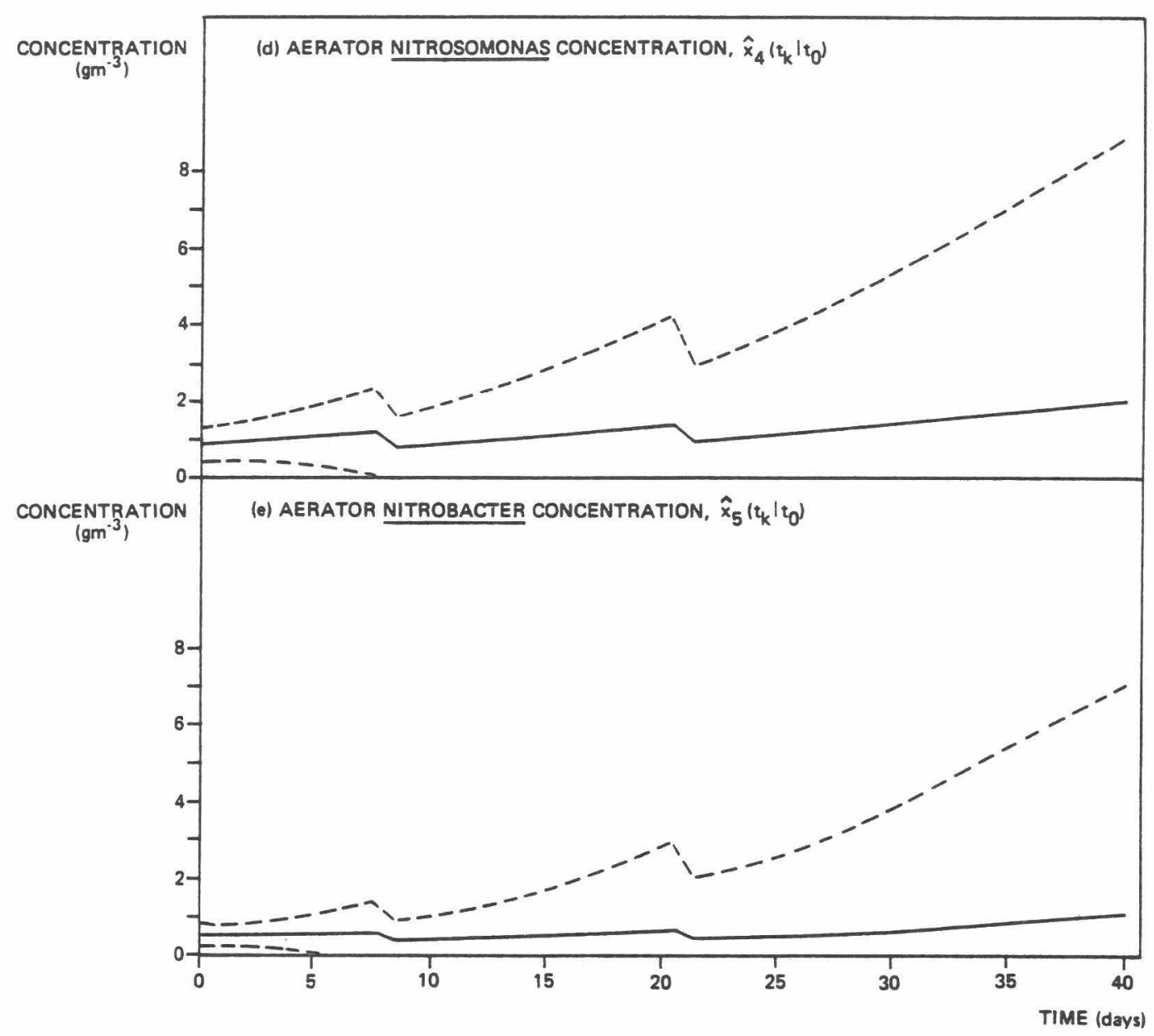

Fig. 7. "Bad" scenario: predictions $\hat{\mathbf{x}}\left(t_{k} \mid t_{0}\right)$ for the aerator concentrations of (a) ammonium-N, (b) nitrite-N, (c) nitrate-N, (d) Nitrosomonas and (e) Nitrobacter. The dashed lines indicate the variation of the confidence bounds associated with the predictions (indicated by the standard deviation of the prediction errors).

behaviour as a function of relationships among easily measured variables, e.g. input and output substrate concentrations, aerator suspended solids concentration.

(b) The parameters of the model, and, by implication, the specific formulation of the model structure, should represent potentially useful information about process operating conditions. Such choices of the parameters might range from the simplest such quantities, for example, the food/micro-organism ratio and the solids retention time (both quantities are calculated from measurements of other variables), through constants for net biological growth-rates, to such complex quantities as the age-distribution of microorganism cells or parameters representing a "tendency to bulk". It is worth noting in this last respect that Busby \& Andrews (1975) have proposed a model in which the activated sludge is in effect separated into three age-groups, while more recently Holmberg \& Ranta (1978) have reported early practical experiences with algorithms for estimating the age-distribution of micro-organism cells in the activated sludge process.

(c) Associated with the model will be a specification of nominal parameter values representing the defini- tion of ideal behaviour. Adaptive operational estimation of both model states and parameters, since it yields (in effect) the values of the parameters required to fit the model (ideal) to actually observed behaviour, would thus permit detection of when performance moves outside acceptable limits. This contrasts with the previous analysis of the paper, where prior assumptions were made about which values for the model parameters would best fit the observed conditions. The difficulty here, of course, would lie in determining the required operational definition of acceptable limit values for the parameters. Again, however, we may note in passing that Andrews et al. (1979) have already experimented with this concept of estimating the variation of a model parameter value (a reaction rate coefficient for nitrification, in fact) as "... a signal to initiate control for avoiding process failure" (emphasis added).

(d) Special emphasis has been added to this immediately preceding quotation because of the significance that has already been attached to the matter of process failure, the possible role of toxic substance spillages in the analysis of Sections 4.1 and 4.2 being a typical example. The detection of the effects of a toxic 
spillage, however, since this will be reflected as an abrupt change in a model parameter value (see also Table 4), is technically quite difficult and not a straightforward implementation of the type of estimation/filtering algorithm discussed here. Such algorithms are more effective in detecting the slower variations of parameter drift, although considerable related theoretical effort has been devoted to the problem of failure detection (e.g. Digernes, 1980). Nevertheless, as argued elsewhere (Beck, 1980), the importance of detecting abrupt, adverse changes in operating performance is likely to increase with the more widespread installation of treatment facilities, the increasing scale and sophistication of these facilities, thus the increasing probability of equipment failure, and the steadily improving trend in maintaining acceptable average, background levels of pollutant concentrations in receiving waters.

These are indeed preliminary guidelines, and much further research effort is needed, particularly in the area of making a prudent choice of model, to establish even the potential for developing such possibilities in a practical direction.

Our final factor for consideration is the computational effort associated with on-line dynamic models and estimation algorithms. It would probably be at this point that one would consider simplicity and compactness as primary virtues, and especially so with regard to microprocessor applications. Almost certainly, in this context, the model and estimation algorithm used in Section 4 carry with them a surplus computational load. In two recent papers, MarsiliLibelli $(1980 a, b)$ has accordingly adopted a reducedorder modeling approach, initially for the purposes of DO control in the activated sludge process; he has also provided a broader assessment of the potential for microprocessor-based computing applications in monitoring, maintenance, and control for operational water quality management in general (Marsili-Libelli, 1980c). Similar studies have been conducted by Aarinen et al. (1978).

\section{CONCLUSIONS}

The results presented in this paper are part of a study on modelling and operational control of the activated sludge process, with particular reference to the plant at Norwich Sewage Works (Beck et al., 1978). An on-line, recursive estimation algorithm, the extended Kalman filter, has been applied to the two problems of: (i) examining the feasibility of state estimation and state reconstruction as features of operational control; and (ii) evaluation of the use of a model for on-line prediction of short-term variations in future operating conditions. The dynamic model of Poduska \& Andrews (1975) for nitrification in the activated sludge process has been used for this purpose.

The performance of the model and estimation algorithm in addressing the above two problems is reasonably good. However, the model is limited in its ability to characterize nitrifier growth, principally because of the assumption that growth-rate is independent of dissolved oxygen concentration. In addition, the growth-rate is further assumed to be independent of the mixed liquor suspended solids concentration, the model does not characterize the dynamics of the secondary clarifier, and is possibly overly complex in assuming a two-step, as opposed to onestep, conversion process for nitrification. Modifications of the model according to these points could greatly improve its scope and usefulness.

With regard to on-line estimation and prediction, it may be concluded that these kinds of applications of modern control theory have considerable potential. This would be especially true if, for example, a suitably simple model could be coupled with, say, on-line measurements of dissolved oxygen concentration, a variable that is intimately related to many of the complex, interacting characteristics of the activated sludge process (carbonaceous BOD removal, nitrification, denitrification, and sludge bulking) and hence particularly important for operational control purposes. It is also concluded that estimation algorithms might be used in other relatively novel contexts for monitoring "ideal" behaviour and for detecting "nonideal" operating conditions, where the latter might arise from accidental spillages of toxic material or adverse changes in sludge characteristics. The rapid development of microprocessor technology is clearly a significant factor affecting the cost and feasibility of such applications. It would, however, be premature to comment further on the considerable research and development effort that would be needed to translate theory into practice.

Finally, an underlying theme of this paper has been the view that models and information processing algorithms are to be considered as support services in the day-to-day decision-making of operational management of wastewater treatment plants. Plant automation and computerization should neither merely assume the passive role of recording plant performance, nor aim for elimination of the human element from the control function. Rather, these technological innovations should be designed to meet and encourage an active interaction of man and computer in operational management. Indeed, a survey of factors limiting wastewater treatment plant performance by Hegg et al. (1978) lends substantial support to such an argument. They observed, in particular, that:

"The highest ranking factor contributing to poor plant performance was operator application of concepts and testing to process control."

“... present plant personnel are an untapped source for achieving improved performance."

Recent preliminary studies (Beck et al., 1978; Tong et al., 1980; Flanagan, 1979, 1980) on the design of process control schemes that exploit and formalize em- 
pirical operating experience thus follow closely the spirit of these observations.

Acknowledgements-The author is grateful to the Anglian Water Authority, to the University of Cambridge Engineering Department and to IIASA for the support, time and facilities with which to carry out this study. Special thanks are due to Tony Latten, manager of the Norwich Sewage Works, whose continuing enthusiasm is highly valued.

\section{REFERENCES}

Aarinen R., Tirkkonen J. \& Halme A. (1978) Experiences on instrumentation and control of activated sludge plants - a microprocessor application. Preprint, VII, IFAC World Congress, Helsinki.

Aborhey S. \& Williamson D. (1978) State and parameter estimation of microbial growth processes. Automatica 14, 493-498.

Andrews J. F. (1977) Dynamics and control of wastewater treatment plants. In Fundamental Research Needs for Water and Wastewater Treatment Systems (Edited by Sherrard J. H.), pp. 83-92. Proc. National Science Foundation/Association of Environmental Engineering Professors Workshop, Arlington, VA.

Andrews J. F., Sørensen P. E. \& Garrett M. T. (1979) ConControl of nitrification in the oxygen activated sludge process. Preprint, IAWPR Workshop on Treatment of Domestic and Industrial Wastewaters in Large Plants, Vienna.

Beck M. B. (1977) The identification and adaptive prediction of urban sewer flows. Int. Control. 25, 425-440.

Beck M. B. (1979a) On-line estimation of nitrification dynamics. Professional Paper PP-79-3, International Institute for Applied Systems Analysis, Laxenburg, Austria.

Beck M. B. (1979b) Model structure identification from experimental data. In Theoretical Systems Ecology (Edited by Halfon E.), pp. 259-289. Academic Press, New York.

Beck M. B. (1979c) System identification, estimation, and forecasting of water quality-Part 1: Theory. Working Paper WP-79-31, International Institute for Applied Systems Analysis, Laxenburg, Austria.

Beck M. B. (Ed.) (1980) Time-variable water quality management-A policy study. In Real-Time Water Quality Management: Proceedings of a Task Force, pp 30-66. Collaborative Paper CP-80-38, International Institute for Applied Systems Analysis, Laxenburg, Austria.

Beck M. B. \& Young P. C. (1976) Systematic identification of DO-BOD model structure. Proc. Am. Soc. civ. Engrs J. entir. Eng Dit. 102, 909-927.

Beck M. B., Latten A. \& Tong R. M. (1978) Modelling and operational control of the activated sludge process of wastewater treatment. Professional Paper PP-78-10, International Institute for Applied Systems Analysis, Laxenburg, Austria.

Bowles D. S. \& Grenney W. J. (1978) Steady-state river quality modelling by sequential extended Kalman filters. Wat. Resour. Res. 14, 84-96.

Briggs R. (1967) Monitoring and automatic control of dissolved oxygen levels in activated sludge. Paper presented at Effluent and Water Treatment Convention, London.

Briggs R. \& Jones G. L. (1978) Aspects of the automation of the activated sludge processs. J. Inst. Wat. Pollut. Control 439-451.

Busby J. B. \& Andrews J. F. (1975) Dynamic modeling and control strategies for the activated sludge process. $J$. Wat. Pollut. Control. Fed. 47, 1055-1080.

Butler P. B. \& Andrews J. F. (1980) A dynamic model for state and parameter estimation of the nitrifying activated sludge process. Trans. Instrument Soc. Am. 19(3).

Canale R. P., DePalma L. M. \& Powers W. F. (1980) Sampling strategies for water quality in the great lakes.

U.R. $1512-c$
Report No. EPA-600/3-80-055, U.S. Environmental Protection Agency, Environmental Research Laboratory, Duluth, MN.

Chiu C-L. (Ed.) (1978) Applications of Kalman Filter to Hydrology, Hydraulics, and Water Resources. Stochastic Hydraulics Program, University of Pittsburgh, Pittsburgh, PA.

Digernes T. (1980) Real-time failure detection and identification applied to supervision of oil transport in pipelines. Modeling, Identification, and Control 1, 39-49.

Downing A. L., Painter H. A. \& Knowles G. (1968) Nitrification in the activated sludge process. J. Inst. Sewage Purif. 2, 130-158.

Flanagan M. J. (1979) Upgrading the activated sludge process through automatic control. A.I. Ch. E. Symp. Ser. No. 190$) 75,232-242$.

Flanagan M. J. (1980) On the application of approximate reasoning to control of the activated sludge process. Preprint, Joint Automatic Control Conference, San Francisco.

Flanagan M. J., Bracken B. D. \& Roesler J. F. (1977) Automatic dissolved oxygen control. Proc. Am. Soc. civ. Engrs J. envir. Engng Div. 103, 707-722.

Gelb A. (Ed.) (1974) Applied Optimal Estimation. M.I.T. Press, Cambridge, MA.

Gujer W. (1977) Design of a nitrifying activated sludge process with the aid of dynamic simulation. Prog. Wat. Technol. 9, 323-336.

Gujer W. \& Erni P. (1978) The effect of diurnal ammonium load variation on the performance of nitrifying activated sludge processes. Prog. Wat. Technol. 10, 391-407.

Harleman D. R. F. (1978) A comparison of water quality models of the aerobic nitrogen cycle. Research Memorandum RM-78-34, International Institute for Applied Systems Analysis, Laxenburg, Austria.

Hegg R. A., Rakness K. L. \& Schultz J. R. (1978) Evaluation of operation and maintenance factors limiting municipal wastewater treatment plant performance. $J$. Wat. Pollut. Control Fed. 50, 419-426.

Holmberg A. \& Ranta J. (1978) Experiences on parameter and state estimation of microbial growth processes. Preprint, VII IFAC World Congress, Helsinki.

Jazwinski A. H. (1970) Stochastic Processes and Filtering Theory. Academic Press, New York.

Jolankai G. \& Szöllösi-Nagy A. (1978) A simple eutrophication model for the Bay of Keszthely, Lake Balaton. IAHS-AISH Publication No. 125, pp. 137-150.

Kalman R. E. (1960) A new approach to linear filtering and prediction problems Trans. Am. Soc. Mech. Engrs Series D: J. Basic Engng 82, 35-45.

Kalman R. E. and R. S. Bucy (1961) New Results in Linear Filtering and Prediction Theory. Trans Am. Soc. Mechanical Engrs., Series D: J. Basic Engng, Vol. 83, pp. 95-108.

Knowles G., Downing A. L. \& Barrett M. J. (1965) Determination of kinetic constants for nitrifying bacteria in mixed culture with the aid of an electronic computer. $J$. gen. Microbiol. 38, 263-278.

Lech R. F., Lim H. C., Grady C. P. L. \& Koppel L. B. (1978a) Automatic control of the activated sludge process-I. Development of a simplified dynamic model. Water Res. 12, 81-90.

Lech R. F., Lim H. C., Grady C. P. L. \& Koppel L. B. (1978b) Automatic control of the activated sludge process-II. efficacy of control strategies. Water Res. 12, 91-99.

Leonov A. V. (1980) The chemical-ecological modeling of nitrogen compound transformation processes. Working Paper WP-80-86, International Institute for Applied Systems Analysis, Laxenburg, Austria.

Lettenmaier D. P. \& Burges S. J. (1977) Design of trend monitoring networks. Proc. Am. Soc. civ. Engrs J. envir. Engng Div. 103, 785-802. 
Lijklema L. (1973) Model for nitrification in the activated sludge process. Envir. Sci. Technol. 7, 428-433.

Marsili-Libelli S. (1980a) Optimal aeration control for wastewater treatment. In Computer Aided Design for Control Systems (Edited by Cuenod M. A.), pp. 511-516. Pergamon Press, Oxford.

Marsili-Libelli S. (1980b) Reduced-order modeling of the activated sludge process. J. ecol. Model. 9, 15-32.

Marsili-Libelli S. (1980c) The role of microprocessors in water quality management: problems and prospects. In Real-time Water Quality Management: Proceedings of a Task Force (Edited by Beck M. B.), pp. 162-183. Collaborative Paper CP-80-38, International Institute for Applied Systems Analysis, Laxenburg, Austria.

Matsché N. (1977) Removal of nitrogen by simultaneous nitrification-denitrification in an activated sludge plant with mammoth rotor aeration. Prog. Wat. Technol. 8, 625-637.

Moore S. F. (1973) Estimation theory applications to design of water quality monitoring systems. Proc. Am. Soc. cir. Engrs J. Hydr. Dir. 99, 815-831.

O'Connell P. E. (1980) Real-time Hydrological Forecasting and Control. Technical Report, Institute of Hydrology, Wallingford, U.K.

Olsson G. (1977) State of the art in sewage treatment plant control. A.I.Ch.E. Symp. Ser. No. $15972,52-76$.

Olsson G. (1980) Design and operation interactions in wastewater treatment. In Real-Time Water Quality Management: Proceedings of a Task Force (Edited by Beck M. B.), pp. 152-161. Collaborative paper, CP-80-38, International Institute for Applied Systems Analysts, Laxenburg. Austria.

Olsson G. \& Andrews J. F. (1978) The dissolved oxygen profile-a valuable tool for control of the activated sludge process. Water Res. 12, 985-1004.

Olsson G. \& Hansson O. (1976) Stochastic modelling and computer control of a full-scale wastewater treatment plant. Systems and Models in Air and Water Pollution, Symposium Proceedings, Institute of Measurement and Control, London, August.

Paskins A. R., Jones G. L. \& Wheatland A. B. (1978) Kinetics of denitrification in the activated sludge process. Prog. Wat. Technol. 10, 255-260.

Poduska R. A. \& Andrews J. F. (1975) Dynamics of nitrifi- cation in the activated sludge process. J. Wat. Pollut. Control. Fed. 47, 2599-2619.

Proceedings of IAWPR Workshop on Instrumentation and Control for Water and Wastewater Treatment and Transport Systems, London, Stockholm (1977) Prog. Wat. Technol. 9.

Sincic D. \& Bailey J. E. (1978) Optimal periodic control of activated sludge processes-I. Results for the base case with Monod /decay kinetics. Water Res. 12, 47-53.

Stenstrom M. K. \& Andrews J. F. (1979) Real-time control of activated sludge process. Proc. Am. Soc. civ. Engrs. J. Envir. Engng. Div. 105, 245-260.

Stenstrom M. K. \& Poduska R. A. (1980) The effect of dissolved oxygen concentration on nitrification. Water Res. 14, 643-649.

Svrcek W. Y., Elliott R. F. \& Zajic J. E. (1974) The extended Kalman filter applied to a continuous culture model. Biotechnol. Bioengng XVI, 827-846.

Tanuma M. (1980) Water quality management in a wastewater treatment plant. In Real-Time Water Quality Management: Proceedings of a Task Force (Edited by Beck M. B.), pp. 241-260. Collaborative Paper CP-80-38, International Institute for Applied Systems Analysis, Laxenburg, Austria.

Tomlinson E. J. \& Chambers B. (1979) The use of anoxic mixing zones to control the settleability of activated sludge. Technical Report TR 116, Water Research Centre, Stevenage Laboratory, U.K.

Tong R. M., Beck M. B. \& Latten A. (1980) Fuzzy control of the activated sludge wastewater treatment process. Automatica 16, 695-701.

Wells C. H. (1979) Computer control of fully nitrifying activated sludge process. Instrument. Technol. 32-36.

Whitehead P. G. (1979) Applications of recursive estimation techniques to time variable hydrological systems. J. H`drol. 40, 1-16.

Wood E. F. (Ed.) (1980) Real-Time Forecasting/Control of Water Resource Systems. Vol. 8. IIASA Conference Proceedings Series, Pergamon Press, Oxford.

Young P. C. (1974) A recursive approach to time-series analysis. Bull. Inst. Math. Applic. 10, 209-224.

Young P. C. \& Whitehead P. G. (1977) A recursive approach to time-series analysis for multivariable systems. Int. J. Control. 25, 457-482. 
RELATED IIASA PUBLICATIONS

RESEARCH REPORT

Systems Engineering and Microelectronics in Water Quality Management

RR-82-8

Single

M.B. Beck

Reprinted from Microelectronics in the Water Industry, a supple-

copies

ment to the Journal of the Institution of Water Engineers and

free

Scientists (F. Fallside, editor)

\section{EXECUTIVE REPORT}

Operational Water Quality Management: Beyond Planning and Design M.B. Beck

ER-81-7 Single copies free

\section{RESEARCH MEMORANDUM}

Real-time Control of Water Quality and Quantity

RM-78-19

$\$ 3.00$

M.B. Beck

\section{COLLABORATIVE PAPER}

Real-time Water Quality Management: Proceedings of a Task Force M.B. Beck, editor

CP-80-38

Single

copies free

\section{PROFESSIONAL PAPERS}

Modelling and Operational Control of the Activated Sludge Process in Wastewater Treatment

M.B. Beck, A. Latten, R.M. Tong

Fuzzy Control of the Activated Sludge Wastewater Treatment

R.M. Tong, M.B. Beck, A. Latten

PP-78-10

Single copies free

PP-79-7 Single copies free 
